This item was submitted to Loughborough's Research Repository by the author.

Items in Figshare are protected by copyright, with all rights reserved, unless otherwise indicated.

\title{
A test battery related to ergonomics of protective clothing
}

PLEASE CITE THE PUBLISHED VERSION

http://dx.doi.org/10.1016/j.apergo.2003.11.001

PUBLISHER

(c) Elsevier Ltd.

VERSION

AM (Accepted Manuscript)

LICENCE

CC BY-NC-ND 4.0

REPOSITORY RECORD

Havenith, George, and Ronald Heus. 2019. "A Test Battery Related to Ergonomics of Protective Clothing". figshare. https://hdl.handle.net/2134/12493. 
This item was submitted to Loughborough's Institutional Repository (https://dspace.lboro.ac.uk/) by the author and is made available under the following Creative Commons Licence conditions.

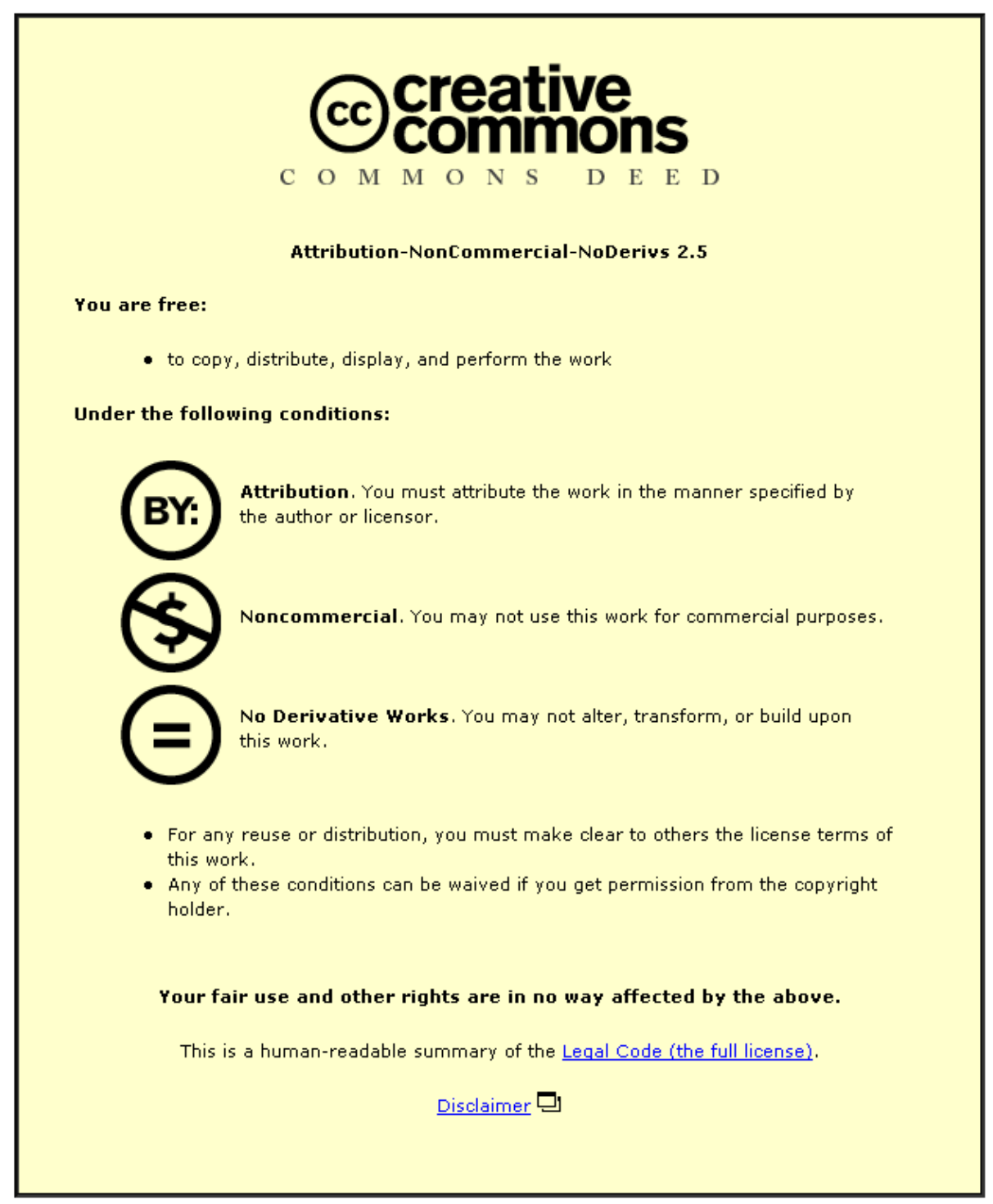

For the full text of this licence, please go to: http://creativecommons.org/licenses/by-nc-nd/2.5/ 


\section{A test battery related to ergonomics of protective clothing}

George Havenith ${ }^{1,2}$ and Ronald Heus ${ }^{1,3}$

${ }^{1}$ TNO Human Factors, Soesterberg, 3769ZG, NL.

${ }^{2}$ Department of Human Sciences, Human Thermal Environments Laboratory, Loughborough University, LE11 3TU, UK;

${ }^{3}$ TNO Industrial Technology, Eindhoven, 5600HE, NL.

Keywords: protective clothing, ergonomics, standards, performance loss, evaluation

Address for correspondence:

Dr. George Havenith

Dept. Human Sciences

Loughborough University

Loughborough

LE11 2SD

UK

g.Havenith@lboro.ac.uk

tel. 01509223031

fax 01509223940 


\section{ABSTRACT}

Specialised protective clothing, as that for firefighters, is usually tested only to standards which give requirements for the materials used (e.g. EN469). However, this testing often neglects the effect the manufacturing process of the garment has on the material properties, the effects of clothing design, sizing and fit, as well as the interaction of the clothing with other components of the standard gear for the profession. Such effects can only be tested by looking at the protective gear as a whole.

This paper deals with methods to do additional testing on protective garments with fire fighter clothing as example. Methods which go beyond EN469. Human subjects test for physiological load, heat protection, ergonomical design, loss of performance, rain/moisture protection and conspicuity/visibility of the clothing are described and proposed for evaluation of protective clothing in general and for further development of standards on firefighter's' clothing.

\section{Introduction}

Testing of workwear and specialised protective clothing is performed on a regular basis for reasons of certification (CE-mark), quality control, development and for information gathering in procurement (Stirling, 2000; Graveling and Hanson, 2000). In the past, such testing has mainly concentrated on the properties of the materials used. A typical example of this can be found in the testing and evaluation of fire-fighting garments. Presently, these firefighter garments are typically tested to standards, which concentrate mostly on requirements for the materials (e.g. EN469). Additional standards are under development, e.g. for assessment of the risk of burn injury using an instrumented manikin (prEN ISO/DIS 13506.2), but mostly tests refer to material heat and vapour resistance, flammability, retro-reflection properties etc. Though all these tests evaluate important properties of the clothing, this testing often neglects the effect the manufacturing process of the garment has on the material properties (stitching, seems, treatments), the effects of clothing design, sizing and fit, as well as the effect of the interaction of the clothing with other components of the standard gear for the profession (respirators, gloves) and how the clothing performs in actual use. As an example: It was repeatedly observed that clothing fabrics that tested excellent in material tests were not effective in actual use as their properties were annulled by the sewing process. This happened in rain barriers, but also in heat protective layers. Such effects can only be tested by looking at the protective clothing ensemble as a whole, and such test should be incorporated in more detail into future PPE standards (e.g. prEN469). 
This paper deals with methods of testing protective clothing ensembles, which go beyond the material standards. These tests, often referred to as tests on the ergonomics of clothing, consider the complete outfit, and involve manikin (insulation) and human subject testing. The tests described here, which will be the human subject tests only, are based on extensive developments of ergonomic testing methods at TNO Human Factors over two decades (Heus et al, 1995, 1999, Havenith 1996, Lotens 1993). Though initially developed for firefighting clothing, these tests have since been applied with success to various other types of PPE (motorcycle clothing, military clothing, chemical protective clothing, protective clothing for construction workers). Human subjects tests for comfort, physiological load, cold or heat protection, ergonomical design, fit, loss of performance, rain/moisture protection and conspicuity/visibility of the clothing will be described and proposed as a basis for further development into standards for ergonomic clothing evaluation. In the description of most of these methods, the example of testing fire-fighting gear will be followed, but the principles of the testing can be used in most types of protective clothing. The data presented are meant as illustrations of the tests, and not in themselves essential to the paper.

\subsection{Selection of tests and conditions}

An important advantage of many material test methods is that they are designed to produce accurate and reproducible results, both within and between laboratories, at minimal cost. In order to achieve this, test conditions are chosen to provide a high sensitivity for differences in the parameter under study. In practice this also implies however that the test circumstances do not always reflect the actual use conditions (Havenith, 1999). Real use conditions can be highly variable however, and it is unfeasible to test clothing ensembles in all possible conditions. Also, one has to realise that when comparing different clothing ensembles, their ranking can be reversed by the choice of the environments. E.g. a garment, which protects extremely well from external heat due to a high insulation, will usually perform badly in conditions where heat loss from the body to the environment is possible and essential. Hence, to narrow down the number of test conditions, and to ensure relevant conditions, the first step in any clothing evaluation should be a proper task and risk analysis. This should identify the main functions of the clothing, during what tasks it would be used, in what environments that would be, and how the different requirements should be rated in terms of priorities (risk assessment, see e.g. prEN469). Doing this should identify the main requirements for the clothing to which subsequently testing procedures can be adapted.

To follow the example of testing of fire-fighting gear, 'typical' scenarios may involve different 'typical' climatic circumstances (these may differ by country and by fire service (see e.g. Bilzon et al, 2001), see Fig. 1): 
Indoor fire attack

High air temperature, medium to high radiation, smoke, water exposure, and high activity levels

\section{Outdoor extinguishing activities}

Low air temperature, low to high radiation, water exposure, low to high activity levels Roadside rescue

Ambient temperature, low radiation, exposure to rain, low to high activity levels, risk from traffic

\section{FIGURE 1 ABOUT HERE}

Within these scenarios, typical aspects of the clothing that may be considered as determining clothing performance are:

- Insulation (protection from cold, heat [conductive, convective and radiant])

- Vapour permeability (sweat loss capacity)

- Air permeability (affecting heat and vapour resistance and penetration of pollution)

- Visibility/conspicuity

- Liquid protection (repellency of water and chemicals, waterproofness, absorption)

- Mechanical protection

\subsection{Test criteria}

Identical tests with human participants, performed in different laboratories are notorious for their variability of results, mostly due to difference in the groups of participants used. As we are discussing testing using human participants in the context of comparative testing or testing according to standards, it is important to consider the problems of test result reproducibility and comparison of the results to acceptability criteria. The general problems related to using human participants will be discussed later, but the relation to acceptability criteria needs to be discussed before discussing the separate tests.

As test results will be influenced by the population used for the test, it is difficult to set absolute performance criteria for the clothing. This is e.g. a problem with the proposed ergonomic/physiologic performance test in the revision of EN469. However, there are ways to standardise the results.

The first is to use a reference suit, to which all results are compared. This could be a tracksuit for all experiments where protection is not an issue but e.g. freedom of movement is. Performance reductions can then be expressed relative to this reference suit (in \% performance loss) allowing a better comparison across experiments and laboratories. For the protection properties a reference suit can be used or, in case of testing for procurement, the current in-service garments. 
When larger numbers of different products are tested, an alternative is to use ranking tables of the products to identify 'best on the market' versus 'average' and 'low' performers. The selection of the approach to be used is very much depending on the reason for performing the tests (procurement, certification, development).

\subsection{Statistical aspects of comparisons}

In order to compare garments with each other or to a reference garment it is not sufficient to look at the differences in the results (means). It is essential that differences be tested statistically in order to determine the likelihood of observed differences being due to chance. Typically two types of data will be collected: objective and subjective. For most objective data (temperatures, performance losses, water leakages) a parametric test can be used: typically repeated measures analysis of variance (ANOVA) with post hoc comparisons of individual suits (Tukey). Often paired t-tests are used for these types of comparisons, but given the large number of possible comparisons when more suits are tested at the same time, this should not be done without applying a correction to the significance value (Bonferroni; divide the required significance level by the number of planned comparisons). ANOVA with a Tukey post hoc test takes care of this problem. For subjective data (sensations), a non-parametric test should be used, e.g. a Friedman test (or Wilcoxon rank test on pairs with Bonferroni correction). Some subjective scales (e.g. temperature sensation) have been shown to have the required characteristics for application of parametric tests.

The tests design is always a within subject design. Each participant wears all the suits, and thereby acts as their own control. Individual differences between participants are in this way extracted (repeated measures test) from the results. As discussed in the section on test sensitivity, the typical (minimal) number of participants will be around 8 to gain enough sensitivity. Discriminative power between clothing systems increases with increasing participant numbers. The wearing order of the various suits will have to be balanced (not randomised!) over participants to avoid order effects (participants getting acclimatised or getting worn out or less motivated with time). Typically, Latin Square designs are used that avoid effects of order of testing to become an issue (see appendix E).

For all tests a significance level of $\mathrm{p}<0.05$ is required to accept that differences observed are real (a chance of 1 in 20 that a difference found is nevertheless due to chance). For the rest of this paper, where significance is stated this therefore implies a p-value below 0.05 .

\subsection{Ethical Considerations}

It is generally accepted that investigations on human beings should be governed by codes such as those of the World Medical Association (The Declaration of Helsinki, 1964; revised 1975). It is now commonplace for ethical committees to have been established within organisations to supervise the ethics of investigations involving human participants. There should be an acknowledged obligation to protect the participants from possible harm and to preserve their rights. For the experiments described 
here such considerations should be applied. Part of this consideration will be to weigh the risks for the participants against the benefits of the investigation. Risks should of course be minimised wherever possible and before starting an investigation risks should be explicitly assessed and stopping criteria for the tests defined. Participants need to be made aware of any risks and countermeasures taken and should give their informed consent. For the physically demanding testing, medical screening may be required. Using participants from outside the relevant profession will require further measures as they may not be aware of risks involved or may show unexpected responses. Guidance for stopping criteria may be obtained e.g. from ISO 9886 (2003), which suggests safe limit values for occupational exposures. However for experienced laboratories, with trained personnel and healthy fit participants, higher limit values may be acceptable when the participants are closely monitored.

\section{Proposed test battery}

In addition to measuring/determining the clothing parameters mentioned earlier in materials tests, they should now be determined in relevant scenarios. The main protective and other functional aspects of the clothing present in the fire fighter scenario's can be determined in the following tests:

\subsection{Test for climatic protection}

This test aims at the protective capacity of the clothing, so it refers to the extremes of the climates for which the clothing was designed. For cold weather clothing this would be a cold tolerance test; for the firefighter's clothing a heat (high temperature and/or high radiation) protection test.

\subsubsection{Firefighters; relevant scenario's}

Typical scenarios for climatic protection for firefighters relate to exposures where tolerance times (exposure times) are limited by the level of protection against high temperatures or high radiant heat loads. The high radiant load will increase suit temperature and the heat can penetrate the suit fast leading to skin burns.

\subsubsection{Experiment:}

Different ensembles are compared to each other and to a standard protective outfit or the clothing currently in use, using a within subject design. Each participant $(n=8)$ wears all clothing types in a balanced fashion to avoid any order effects on the results. The participants, wearing the clothing including SCBA (Self Contained Breathing Apparatus), are exposed to very high radiant loads (7 $\mathrm{kW} . \mathrm{m}^{-2}$; simulating close proximity to a fire source. For comparison: tropical sun radiation is maximally $\left.1 \mathrm{~kW} \cdot \mathrm{m}^{-2}\right)$ in a hot chamber $\left(>100^{\circ} \mathrm{C}\right)$. In front of well-controlled propane burners (Fig. 2) delivering this heat load, they perform a light bench stepping exercise. The determinant factor for this test is the radiant load, as within the exposure time the air temperature has little effect and is therefore 
less critical. The clothing will increase in temperature very quickly, as will skin temperature. The function of the exercise is not to add an internal heat load, but to keep the clothing moving to and from the skin. A high risk of burns would be present if clothing was left static. In that case its temperature could increase to very high values unnoticed, and then when the person wanted to withdraw, the hot clothing would touch the skin and cause a burn. Experience has shown that participant's voluntary withdraw consistently at skin temperatures around $44^{\circ} \mathrm{C}$. Thus, as long as precautions are taken that the clothing isn't static, with the associated risk of high clothing temperatures, no risk of skin burns in this type of testing is present. Over many tests, using both professional firefighters and inexperienced participants, no burns occurred.

\section{FIG 2 ABOUT HERE}

The test is repeated with dry and with moist underclothing (300 g water distributed over undergarments to simulate sweating), and with the radiation on the front and on the back.

The clothing's performance is measured as the tolerance time. This is either defined by the participants' withdrawal (high skin temperature sensation), or by any skin temperature of the participant (measured with thermistors or thermocouples on the exposed side coming within $1^{\circ} \mathrm{C}$ of the pain threshold limit of $45^{\circ} \mathrm{C}$ ). The maximal exposure time for this test is currently set at 120 seconds. As it is impossible to cover the whole skin area with temperature sensors, it was found that the subjective withdrawal provides the best information. Body core temperature measurement is not needed in this test considering the short exposures. However in case of many test repetitions it may be advisable to monitor cumulative load purely for safety reasons. In principle participants should be in a cool environment between tests to bring them back to the same starting condition. The clothing into which they change should be conditioned in a constant environment to assure constant starting conditions.

For additional information, the suits are equipped with temperature sensors, which record the maximal suit surface temperatures, and the participants are afterwards asked to fill in questionnaires regarding their experience.

In the experiment described as example here, 7 firefighting suits were compared. Though for this paper their detailed specification isn't relevant, a brief description is given an Table 1. The results are compared to the 'reference' suit, which was the in-service suit at the time of the test.

\section{TABLE 1ABOUT HERE}




\subsubsection{Results/Interpretation:}

The protection of the suits against extreme heat was quite different for the different conditions. This becomes evident when the tolerance times of all suits are compared for all circumstances (table 2).

\section{TABLE 2 ABOUT HERE}

With moist undergarments the tolerance time was longer than with dry undergarments. When exposed to radiation from the front this effect was stronger than when exposed from the back.

On the dry conditions, and when radiated from the front, suits $\mathrm{M}, \mathrm{V}$, and A performed very well with tolerance times close to the pre-set limit of two minutes. When the suits were radiated from the back, mainly suits A, P, M and the two-part $\mathrm{H} 2$ protected very well.

Under moist conditions and with radiation from the front suits $\mathrm{A}$, the reference suit, and $\mathrm{M}$ which performed well with a maximal tolerance time. Also when the radiation came from the back, these suits offered the most protection.

The temperatures measured at the outside of the suits only showed significant differences when radiated from the front in the dry condition (figure 3). Suits $\mathrm{M}$ and V showed significantly higher temperatures on the outside of the suit then the other suits.

When the relation between suit surface temperature and tolerance time is studied, then according to the expectations, the temperature was higher as the tolerance time increased (figure 4). When the suit provides more protection, the outside of the suit will be exposed to the radiation for a longer time, and thus the temperature of the outside of the suit will increase more.

A remarkable finding however is the reaction of suit A to the exposures. In this case a long exposure time produced relatively low suit temperatures. This was caused by a higher evaporative heat loss from this woollen suit. In this case parts of the received heat was used to evaporate moisture (regain) naturally present in the suit. The amount of regain is much higher for natural fibres (wool) than for Aramids and other man-made fibres. This resulted in a lower increase in temperature of the suit surface. The quantity of evaporated moisture has not been measured in this test, but the explanation is consistent with the results obtained in the physiological load test (sweating efficiency) that will be described hereafter. Based on these results of Table 2, the tested suits can be compared to the reference suit (table 3).

\section{FIGURE 3 AND 4 ABOUT HERE}

\section{TABLE 3 ABOUT HERE}

The results of the questionnaire (Appendix A, Question 1) showed that depending on the side of the suit that was radiated, significant differences appeared in subjective temperature judgements. When 
the protection against heat is considered overall, the subjective votes in relation to the temperature sensation for the leg, the arm, and the belly showed differences (figure 5).

\section{FIGURE 5 ABOUT HERE}

The temperature sensations for the back did not differ between suits, but this was mainly caused by the presence of compressed air bottles that were carried in a frame on the back, which provided additional protection against the radiant heat. The result of the questionnaire supports the rating presented earlier. In addition the questionnaire clearly showed that the reason for breaking off the test was usually caused by local high skin temperatures on the upper leg or on the shoulders underneath the straps of the respirator. The complaints noted in relation to suit $\mathrm{V}$ was that it kept "glowing", even after the exposure chamber had been left.

\subsection{Test for physiological load:}

This test aims at determining what physiological load the clothing imposes on the wearer. Hence, it will not look at the protective properties against extreme climates, but consider how the wearer is able to thermo-regulate in conditions where he or she will be able to do so. For this, the climatic conditions need to allow heat loss. This implies that ambient vapour pressure needs to be lower than the saturated skin vapour pressure $\left( \pm 5.6 \mathrm{kPa}\right.$ at $\left.35^{\circ} \mathrm{C}\right)(\mathrm{A})$ to allow for evaporation, or the air temperature to be lower than skin temperature (B), which would allow both dry and evaporative heat loss. The physiological load will be determined by the clothing's vapour resistance (A\&B), it's heat resistance (B) and by it's effect on the wearer's metabolic heat production. The metabolic heat production will be determined by the clothing's weight and it's effect on the freedom of movement (stiffness). The selection of the test condition should be made based on the task analyses/risk assessment.

\subsubsection{Example firefighters; relevant scenarios:}

Typical scenarios are exposures where time is limited by SCBA or by heat strain (indoor fire attack): high air temperature (equal to or above skin temperature!) with medium radiation and medium work load allows for working times up to 30 minutes (new types of 300 bar SCBA may allow longer working times and test limit times may be adjusted for this). The heat strain will be mainly determined by the ability of the wearer to lose his/her body heat through the clothing to the environment. Considering the high air temperatures, dry heat transfer will be negligible or towards the body, and heat loss will have to be through evaporation. Ambient vapour pressure will therefore have to be lower than that of wet skin. 


\subsubsection{Experiment:}

Different ensembles are compared to each other and to a standard outfit or the clothing currently in use, using a within subject design. Each participant $(n=8)$ wears all clothing types in a balanced fashion to avoid any order effects on the results. The clothing, including SCBA, is worn while performing moderate work (walking in changing direction at $\pm 3.5 \mathrm{~km}$ per hour, stepping over low benches $\left[ \pm 225 \mathrm{~W} \cdot \mathrm{m}^{-2}\right)$ in a room with an air temperature of $\pm 60^{\circ} \mathrm{C}$, a black globe temperature of about $95^{\circ} \mathrm{C}$ (see fig. 2) and a relative humidity below $15 \%$ (equivalent moisture content to $100 \%$ at $25^{\circ} \mathrm{C} ; \mathrm{P}_{\mathrm{a}}=3.1 \mathrm{kPa}$ ). Body temperatures (skin [minimal 4 sites] and core [rectal or insulated aural]) are monitored, as is sweat loss and sweat absorption/desorption in the clothing (Havenith et al. 1990) using accurate scales (10 $\mathrm{g}$ whole body; $1 \mathrm{~g}$ clothing).

The clothing's performance is measured in terms of tolerance time, dry heat gain, evaporative heat loss and evaporative heat loss efficiency (sweating efficiency). Subjective ratings of participants (Appendix A) are taken as well. Tolerance time is calculated as the time for the wearer to reach an 8

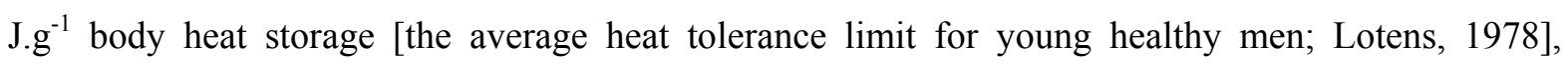

formula: Heat Storage $=\left\{0.8 \cdot\left(T_{\text {core }}-37.\right)+0.2 \cdot\left(\bar{T}_{\text {skin }}-33.5\right)\right\} \cdot 3.48$ Joules. $g^{-1}$. The adherence to accepted safety limits for these exposures is crucial considering the high levels of stress imposed (Malchaire et al, 2001).

As illustration, results from a test on the garments presented in Table 1 will be discussed.

\subsubsection{Results:}

Table 4 shows the results for the tolerance times. In this case, statistical analyses using analyses of variance did not show any statistical significance of the observed differences in tolerance times. The designs and material choices of these garments were very similar, apart from the woollen suit 'A'.

\section{TABLE 4 AND 5 ABOUT HERE}

There were differences between the suits in both the wet (evaporation) heat loss as well as in the dry heat loss from the body (table 5). The evaporative heat loss is the amount of energy used to evaporate produced sweat (2430 Joules per gram of evaporated sweat that cools the body). Suit A reached a high-score in these experiments, which implies that it had the highest evaporation. However this suit also let the largest amount of dry heat through towards the wearer due to its lower insulation. The evaporated heat loss in this climate was therefore mainly used to lose the additional dry heat, which was absorbed from the environment ('negative loss' as the temperature gradient was coming from environment to skin). In environments where the ambient temperature is close to or lower than skin temperature, this garment would have a strong advantage over the others. 
Dry and evaporative heat losses were both measured at the level of the outer garments and not at the level between innermost clothing layer and skin. Dry and evaporative heat losses were therefore influenced by the amount of moisture that the (pre-conditioned) clothing contained.

The protection against heat provided by a higher clothing insulation can have a secondary effect of reducing evaporation of produced sweat (Havenith, 1999). As in the experiments both sweat production as well as sweat evaporation were determined, the sweating efficiency (evaporation sweat/produced sweat) could be calculated (figure 6).

\section{FIGURE 6 ABOUT HERE}

The higher the sweating efficiency is (the more of the produced sweat has been evaporated through the clothing) the better. The highest sweating efficiency was observed when the participants wore suit A (1.18). This value is significantly different of the others suits, with exception of the reference suit (0.97). The lowest value was observed for the two-piece H2 suit (0.58). The value of suit A above 1.0 is of course suspect, as one would not expect a ratio above 1. A ratio above 1 implies that more was evaporated than produced, which at first sight seems impossible. However, this suit was made of wool, and comparing the weights of the clothing before and after the exposures, it was clear that the clothing itself lost part of the moisture. With wool having a high regain, this is substantial, and though it will not directly represent heat loss from the wearers skin, it does represent cooling (heat of evaporation) of the suit itself that will benefit the wearer. Overall, the suits without a waterproof membrane showed better physiological performance than those with.

The questionnaire (appendix A) results for the temperature and humidity sensation showed significant differences between the suits (figure 7).

\section{FIG 7 ABOUT HERE}

\subsubsection{Interpretation:}

Though no significant differences in tolerance time for the climate used were observed, the results provide valuable information. E.g. the results of table 5 show that suit $\mathrm{A}$ had the lowest insulation and vapour resistance. Thus, when ambient temperature is lower than skin temperature, or temperature is equal but vapour pressure lower than that of the skin, this suit will have the lowest physiological load. In the tested environment, with its high $\mathrm{T}_{\mathrm{a}}$, the higher evaporative heat loss in this suit was negated by the high dry heat gain. The high evaporative capacity was reflected in the dryer sensation of the participants ('moist' instead of 'wet'), but coincided with a slightly higher temperature sensation. These findings, together with the lowest 'heat gain - heat loss' value of all suits should give this suit the highest ranking for (low) physiological load. When considering the 
other suits in the same way, a similar consistent picture is visible in terms of heat and vapour resistance, sweating efficiency and thermal sensation.

Integrating these results, together with the decision which climate is most important in terms of risk analyses, allows to give a ranking to the tested suits. Assuming a high weight is given to work in neutral to slightly warm climates the ranking would be:

low physiological load (equal to reference suit): suits A, REF

medium physiological load (slightly worse than reference suit): suits M, H2, P

high physiological load (worse than reference suit): suits V, HC

The most interesting finding for suit A was that it performed well here based on it's low insulation value, but despite the low insulation also performed well in the radiant heat test discussed earlier. The reason for this was the strong effect the fabric's regain had on the results, giving suit A an advantage in both scenarios. Hence, when garments are made of different materials, one has to be careful in 'extrapolating' results to other conditions.

\subsection{Water protection}

This tests relates to the protection of the clothing against water while worn in relevant conditions of movement and wind. This makes the test different from most leak-test manikins, who are usually static in a rain-tower (Heffels, 2000). Having the participants perform light work while exposed to defined rain, including bending over, kneeling etc. (if relevant to their occupation) an additional dimension is added to the test. Also wind can be added, which is e.g. relevant for (motor)cyclist's clothing. This will produce additional (water)pressure on the clothing and test the interaction of the watertight material with design and fit (Havenith, 1996).

\subsubsection{Firefighters; relevant scenarios:}

Water protection is typically relevant in exposure to neutral ambient conditions where 'comfort' and health risks are determined by rain or spray-water protection (e.g. road side rescue).

\subsubsection{Experiment:}

In the same within-subject design as above, the clothing is worn in a well-defined artificial rain environment (e.g. constant rainfall at a rate of $20 \mathrm{~mm} \cdot \mathrm{h}^{-1}$ ). This cannot be performed in natural rain, as conditions may vary too much between trials. Participants need to walk in line with the others while doing a small obstacle course at low speed. This consists of climbing over objects, as well as crawling under objects (kneeling) and e.g. moving crates from low to high positions and vice versa. These movements test the design of the clothing (no gaps when bending over), the waterproofness of materials, seems etc., in normal conditions and under pressure and stretch (knees, elbows). The clothing's performance is measured in terms of water absorption, water penetration to the 
underclothing (both by weighing the respective garments), the leakage locations and the participant's subjective judgement. As wettedness can affect the freedom of movement in the clothing (extra weight, stickiness,..) this point was addressed in the questionnaire (appendix B).

\subsubsection{Results:}

The increase in weight of the suits due to water absorbed in the suits showed substantial and significant differences between the various fire-fighting suits (figure 8). On one hand suit $\mathrm{M}$ absorbs very large quantities of water in the 20 minutes of the test. On the other hand one can see that the reference suit absorbs only a minimal amount of water. Also the coverall HC absorbs relatively little water. When the questionnaires are analysed to study the sensed leakage for each suit it is clear that suit A scores bad (figure 9).

\section{FIGURE 8 AND 9 ABOUT HERE}

The experienced limitation in the freedom of movement that was experienced by the test participants under wet conditions was related to the clothing worn (figure 10). Remarkable differences can be seen in the results for the different suits as to freedom of movement. The coverall $\mathrm{HC}$ and suit $\mathrm{V}$ reduced the freedom of movement more than all the other suits. The scores for the question of the presence of irritating (scouring) spots in the clothing look similar to those for the freedom of movement (figure 11). The more the suit limits the freedom of movement, the more the skin is irritated (scoured) by the clothing.

\section{FIGURE 10 AND 11 ABOUT HERE}

The total rating for rain protection (table 6) is compiled based on the experienced leakage (figure 9), the hindrance caused by the wet clothing (figure 10 and 11) and the quantity of water absorbed (figure 8). No criteria are available to calculate a weighted score for rain protection. The experienced leakage provides more information for the rain protection of the firefighter (figure 9) then the quantity of water absorbed in the clothing, as the moisture absorbed often had accumulated in the outermost layer of the clothing. The score for the reduction in the freedom of movement under wet conditions is considered more relevant in respect to ergonomics of the clothing and less to rain protection. Therefore this value was only considered in respect to rain protection when the suits had equal scores on other tests.

\section{TABLE 6 ABOUT HERE}


Water absorption by the clothing, when no leakage is present, is not necessarily a disadvantage as was shown in earlier experiments (Lotens, 1987). It was shown that moist clothing could increase the tolerance time. The absence of leakage in this case is essential however as when direct contact of the skin with a hot surface occurs, the tolerance time in wet conditions is strongly reduced (Holewijn et al., 1991) and steam transport towards the skin is possible.

\subsection{Freedom of movement}

The freedom of movement test takes account of the design and fit of the garments in relation to their effect on task performance. For this purpose, the participants need to perform task-related activities. Actual task related activities are difficult to repeat accurately for all suits to be tested, however. E.g. for firefighters, ease of donning the suits in a driving truck is a practice related task, but it would be extremely difficult to reproduce the exact driving conditions for each session. Instead, one can consider 'simplified' tasks that nevertheless have a relation with actual task performance. This should preferably be validated for the profession studied, and for the tests described here a good correlation with actual firefighting task performance was shown by Lotens (1982).

In addition to the performance measurements, questionnaires taken during these tests, as well as during all other test described in this paper (rain test, physiological load), provide essential information on the ergonomic properties of the clothing.

\subsubsection{Firefighter; relevant scenarios:}

Typical scenarios are those where task performance is related to freedom of movement. This is determining movement speed, flexibility and energy expenditure. Any hampering of the wearer's movements increases risk.

\subsubsection{Experiments.}

In the same within-subject design as before, participants in the gear (without SCBA to make the test more sensitive to the clothing differences, or with to emphasize the interaction of the SCBA with the suit) are asked to complete an obstacle course at maximum speed. This involves relevant activities for the profession (climbing ladders, through windows, over, under and through obstacles). The clothing's performance is measured in terms of time to complete the obstacle course, in relation to the time to do it in a training suit. In addition various small tests (time needed for donning, $80 \mathrm{~m}$ sprint, running in 8 shaped pattern underneath a lowered bar, sit and reach and stand and reach test, sargeant's jump can be added to evaluate the way in which the clothing hampers the movement. For tests where time to complete the test is measured, performance reduction is calculated as:

$$
\text { performance reduction }=\left[1-\frac{\text { time in reference clothing }}{\text { time in test clothing }}\right] \cdot 100 \%
$$


and for tests where performance is scored in number of repetitions within fixed period:

$$
\text { performance reduction }=\left[1-\frac{\text { number of repetitions in test clothing }}{\text { number of repetitions in reference clothing }}\right] \cdot 100 \%
$$

The results on the tests "sprint" and "eight "of the ergonomics tests, which mainly look at extreme loads (speed and co-ordination) showed that most suits had similar effects on performance. Also for a firefighter specific task as the obstacle course no differences between the suits were observed. A difference was observed in the speed of donning the clothing (figure 12).

\section{FIG 12 ABOUT HERE}

The questions in the questionnaire (appendix C) are aiming at the large number of use properties of the fire-fighting garments. All in all, roughly four categories can be discriminated: donning and doffing, fit, comfort, and compatibility.

Several of the questions related to the ease of donning and doffing produced significant differences between the suits. Suit A performed best in this test. Normally, one would have expected the coverall $\mathrm{HC}$ to have an advantage in this respect. However, as the sizing system for the coverall was far from ideal for most participants, a loss of performance in relation to the reference suit was observed for the coverall as well. When results for the coverall were separated in those for participants with a too small suit and those for participants with the proper size suit, it was shown that as expected the coveralls that fitted properly indeed had an advantage in relation to all other suits in the tests. Suit M showed below average performance on most categories, but the rigidity and the thickness of the material can explain this. This suit was stiffer than the others. In contrast to the stiff suit M, the twopiece $\mathrm{H} 2$, the reference suit, and suit A were made of very supple materials and these scored above average. Table 7 shows the overall judgements of the suits for the four different categories. The total score given in table 7 is an average over all properties of use, for which there are no absolute criteria or weighting factors available, but in which the plusses and minuses of the scores on the various ergonomics related tests are compiled and integrated. A slight preference for suit A and the reference suit was present, whereas suit $\mathrm{M}$ and the coverall $\mathrm{HC}$ scored below average on all parts in the questionnaire. 


\subsection{Ergonomical design assessment}

As the clothing is only worn for brief periods during these tests, not all ergonomic problems may surface. Hence, an assessment by an ergonomist and/or expert on the profession can provide additional info.

\subsubsection{Relevant practical requirements:}

When all the clothing and equipment worn during a certain task is combined the clothing still should be functioning properly and provide the basic functions (protection, storage, etc.) to the wearer.

\subsubsection{Assessment:}

For this aspect an expert panel (ergonomics and topic specialist) assesses the clothing. While the clothing is worn by participants of different statures and builds, as well as by panel members, the clothing is evaluated for freedom of movement, proper design (overlap between jacket and trousers, arm length), compatibility with other equipment (e.g. accessibility of pockets while SCBA is worn, design and types of zips, buttons, fasteners). The clothing performance is measured using consumer evaluation type tables (scores: much better, better, equal to, lower/worse etc. than average or than old suit or a reference suit).

\subsubsection{Results}

As results for this section are highly specific to the individual suit and hence not very informative to the reader in a generalising manner, these are omitted.

\subsection{Visibility/Conspicuity}

In many professions, visibility and conspicuity of PPE is important for the wearer's safety. Often tasks are performed among moving machinery (roadworkers, police), or in places where people might get lost and need to be rescued (off-shore, helicopter pilots). In such cases they should be easily spotted (car-drivers, search teams) and recognised as humans. The latter is particularly relevant when considering a rescue site with large numbers of rescue vehicles present, which all have high visibility features which may make the workers themselves less conspicuous in the overall picture and thus increases risk.

\subsubsection{Relevant practical conditions:}

Exposure during tasks where the wearer's visibility is important. Any activity in traffic, or in obscure areas will have a high risk if visibility of the wearer is insufficient. 


\subsubsection{Experiment:}

As day- and nighttime visibility are separate issues because of the different material types used for these, this requires two separate experiments. The experiment described here deals with night visibility. The daytime visibility can be determined in a similar way, without a direct light source but with low level diffuse lighting instead.

As not only the materials used and their total surface area, but also the patterns used are relevant in this case, tests are done in a set-up modified from the CEN tests on retro-reflective clothing materials (EN471; fig. 13). In a set-up simulating lighting condition of a car approaching in full darkness, using the car's driver viewpoint when the car is 100 meters away from the subject, pictures with defined exposure time and aperture are taken of the suits in frontal, lateral and rear view. Later, these pictures are evaluated by the expert panel. The clothing's performance is measured in terms of visibility of the subject (total visible surface, which can be analysed with software [absolute area] or by the panel [conspicuity ranking]), as well as in terms of recognition as a human (pattern of visibility material). At this time, no good sample material from fire-fighting garments was available. Instead data from a motorcycle garment comparison are presented.

\section{FIGURE 13 AND 14 ABOUT HERE}

\subsubsection{Results:}

Examples of a series of pictures taken from protective suits for motorcyclists (seated position) are given in Fig. 14 (Havenith et al. 1996). These pictures show a difference in the distribution and amount of retro-reflective material. No human form is visible in the front and back view, and also the side view shows only limited human shape, especially in C. Whereas this shape aspect may be less relevant for the motorcyclist while located on the bike which provides the context for the observer, it is very relevant for workers that may be present on roads out of their normal context, as rescue workers and firefighters. The total visible surfaces of the suits differ, with suit $\mathrm{C}$ having only a fraction of the side surface visible compared to suits A and B.

\section{Discussion}

\subsection{Test selection}

The test battery described here represents a series of tests that in the past have been shown to discriminate between clothing ensembles in a meaningful manner. The test battery is not exhaustive. 
With this testing one should keep in mind that a large investment of time and cost is involved, and therefore one should always make a selection of tests that is most relevant to the specific clothing that is under investigation. For this reason, it is essential that the experimenter tries to anticipate what kind of results he or she may get from a test and actually consider the usability of such results in the evaluation. To give an example about selecting the conditions: when one wants to test whether clothing has sufficient 'breatheability' (i.e. high vapour permeability) one should allow vapour transport in the selection of the climate. If one would test in environment with vapour pressure equal to the skin's, one would never find any differences between garments due to the absence of a vapour pressure gradient and results could not be interpreted for other conditions. The test then is superfluous as results could have been predicted. Trying to differentiate between breathable membranes for firefighter clothing in a firehouse test at extreme temperatures, where vapour pressure of the environment will be higher than that on the skin, and where thus no vapour will leave the skin is an example of choosing the wrong test conditions. On the other hand such conditions are good for testing the heat protection of suits, however that is a different question.

Another point related to test selection is that the tester or the representative for the profession should in advance consider what they would do with the results and what priority they would give them. E.g. testing suits at a low temperature and vapour pressure will generally give the opposite ranking to testing these suits at very high temperatures and vapour pressures due to their insulative properties. If one isn't able to give priority to one of these conditions for the task performance, there is no use in doing the tests as no overall conclusions could be drawn.

\subsection{Test sensitivity}

In the examples used here, differences between garments were statistically insignificant in several tests. In earlier experiments (Holewijn, 1991, Lotens, 1993) clear differences were observed, but as the clothing was developed further based on these earlier tests a convergence of clothing designs over time could be observed leading to a reduction in the size of the differences. Lotens (1993) investigated the sensitivity of several of the tests described here. For the climatic load test he found that with 8 participants, the minimal detectable significant difference (MDD) between suits was 10 seconds on exposures up to $120 \mathrm{~s}$. For the physiological load test, the MDD was 4 minutes on 25 minutes. For the performance loss it was $5 \%$, for the ergonomic evaluation $1 / 2$ a category, for the absorbed water in the waterproofness test $200 \mathrm{~g}$ and for the experienced leakage $1 / 4$ of a category. This sensitivity will obviously vary slightly with different participant groups, and sensitivity can be improved by increasing the participant number. Eight participants seems however to be a minimum to observe relevant differences. It should be noted that in some standards only 4 or 6 subjects are requested, which often leads to lack of statistical power and may lead to erroneous conclusions that no differences are present between garments. 
In the current test, scores for the various suits had improved above previous tests with older clothing designs. This caused more suits to reach the maximal exposure times allowed, and this obviously reduces the discriminative power of the test. Hence it should be considered whether either the heat load should be increased to stay with current limit times, or whether limit times can be increased. In the light of development of new, longer lasting SCBA, a longer time limit may be realistic and could be used in the test. This would increase the discriminative power, as typically differences become more pronounced over time.

It is important to note however, that even with these garments scoring very close to each other, in the tests performed a vast amount of subjective information was gathered which allowed discrimination between the various designs and which was considered highly valuable by the sponsor of the project.

\subsection{Test validity}

The first step in assuring the validity of the presented tests is assuring that the test types and the test conditions match those that emerge as most relevant from the task/risk analyses. As discussed earlier, using unrealistic conditions may give results that cannot be translated into practical use. For the tests here, the firefighting brigades were involved in the test design, and the test participants (for this clothing mostly professional firefighters) asserted that their experiences in the test were typical for real use. Lotens and van de Linde (1982) tested whether the performance tests used here were valid for actual firefighting work. They compared the results of a test of three suits for the test battery with those on a battery of actual fire-fighting tasks (rolling out hoses, dressing in a driving fire engine etc). They observed a slightly non-linear relation between both test batteries, but suits scored equal on both in relative terms.

\subsection{Short term versus long term wear trials}

The tests described here are short-term tests. Long-term user trials (Behman, 1988, Lotens, 1989) would provide additional information on ageing and wear and tear of materials and haberdashery. Considering the cost implications of such tests, they are only feasible in very large procurement projects (e.g. military), and go beyond the scope of the present paper. In such wear trials a lot of information is gathered by questionnaires and regular inspections of the clothing. In the tests described here, part of that information is collected by the questionnaires filled in by the participants after each test. As can be seen in the individual test's descriptions, a lot of information becomes available in this way. The actual test procedures, apart from providing objective data, have an important second function in this respect. This is to get the participants in the test clothing through task-related activities that will bring to light shortcomings in wearability, compatibility, design, sizing, production quality, quality of zippers, fasteners, seems, etc. E.g. the sizing problem observed 
in suit HC was related to that manufacturer's sizing system and/or his quality control. In this respect the questionnaires that were filled in by the participants after each test revealed many of the clothing's smaller faults as low quality zippers, misplaced pockets, scratchy seems etc. These problems need to be collated and addressed in the test report.

\subsection{Integration of results}

The tests described above provide a vast amount of data. As seen earlier, it is difficult to integrate results for a single test as suits may differ on various aspects for which the order good-bad is not the same. Integrating all test's results is even more complicated as there the weighing of the different test into a final judgement is highly critical. The latter, giving one final judgement, is in practice seldom possible. Only if clothing for a very specific situation is tested, the weighing may be feasible. For most situations however, the final application is less explicit. For firefighter garments e.g., the usage may be very different between different brigades. In such cases the results should be summarised in consumer association type tables, where the people responsible for procurement can select suits according to their own requirements in relation to their performance on individual tests.

\subsection{Test reproducibility: human subjects as evaluation tools}

As mentioned before, material test standards are geared towards accurate and reproducible results. In the tests proposed here, measurements are performed using human subjects as 'evaluation tools'. This implies that the experimenter will have to expect human variability to influence the results. While inter-participant variability is desirable in order to evaluate the PPE for use by different populations (e.g. sizing effect), intra-participant variation (differences between days for the same participant in the same condition etc.) is undesirable and efforts should be made to minimise this. Pre-test conditioning of clothing and participants are thus important, as is the participants' motivation level, which needs to remain high. Though this variability will not produce bias in the data if the experimental design is properly balanced, it will increase noise levels in the data. Experience shows that the tests described here can discriminate well between different clothing ensembles for various PPE types, and that they are very sensitive in exposing typical weak spots in the clothing design or manufacturing process. We are therefore convinced that adaptation of these or similar test procedures for use in PPE standards would advance the quality of PPE testing substantially.

\section{Acknowledgements}

Parts of this work were funded by the Netherlands Ministry of Defence and the Netherlands Ministry of Internal Affairs. Special thanks goes to Ing. J. Heukelom, BSc for his stimulating enthusiasm for promoting these methods under end-users of fire fighting clothing. 


\section{References}

Behman, F.W., Field evaluation methods. In: handbook of clothing, chapter 16. NATO publication, Biomedical effects of military clothing and equipment systems. RSG-7, 1988.

Bilzon, J.L.J., Scarpello, E.G., Smith, C.V., Ravenhill, N.A., and Rayson, M.P. (2001) Characterisation of the metabolic demands of simulated shipboard Royal Navy fire-fighting tasks, Ergonomics, 44(8), 766-780.

EN 469 (1995) Protective clothing for firefighters, European standard, Brussels: CEN

EN 471 (1994) High visibility warning clothing, European standard, Brussels: CEN

Graveling, R. And Hanson, M. Design of UK firefighter clothing. in: Ergonomics of Protective Clothing, Kuklane, K. and Holmer, I. (eds), National Institute for Working Life, Sweden, Nokobetef 6 and 1st European Conference on Protective Clothing, Stockholm, Sweden, May 2000, pp 277-280, ISBN 917045559 7, [WWW] Available from: www.niwl.se/ah/.

Havenith, G., Heus, R., Lotens, W.A., "Resultant clothing insulation: a function of body movement, posture, wind, clothing fit and ensemble thickness”. Ergonomics 33/1, pp. 67-84, 1990.

Havenith, G., Heus, R., Wammes, L.J.A., Kistemaker, J.A. (1996). Evaluation of six prototypes of army motorcycle suits (Report TM-96-C034). Soesterberg, The Netherlands: TNO Human Factors Research Institute.

Havenith, G., "Heat Balance When Wearing Protective Clothing", Annals of Occupational Hygiene, 43(5), 1999, pp 289-296, ISSN 00034878.

Heffels, P., Rain tightness of protective clothing-prenormative interlaboratory tests using a manikin,. in: Ergonomics of Protective Clothing, Kuklane, K. and Holmer, I. (eds), National Institute for Working Life, Sweden, Nokobetef 6 and 1st European Conference on Protective Clothing, Stockholm, Sweden, May 2000, pp 196-199, ISBN 917045559 7, [WWW] Available from: www.niwl.se/ah/.

Heus, R., L.J.A. Wammes and W.A. Lotens (1992). Qualification of firefighters' protective clothing. Proceedings of the Fifth Int. Conf. on Environmental Ergonomics, Maastricht, November 26, p. 152-153.

Heus, R., L.J.A. Wammes and W.A. Lotens (1992). A comparison of six firefighters garments to a reference suit; simulated tests for general use and comfort (in Dutch). Report IZF 1992 C-12, TNO-Institute for Perception, Soesterberg.

Heus, R., Wammes, L.J.A., Kistemaker, J.A., Havenith, G. (1995). Improvement of the Amsterdam Firefighters garments (in Dutch). Report TNO-TM 1995 C 06. TNO Human Factors Research Institute, Soesterberg. 
Heus, R. \& Heukelom, J. (1999). Fire fighting and human factors; what does EN469 mean for fire fighters, proceedings of the international conference on thermal protection of man under hot and hazardous conditions, March 1999, Paris, France, 51-58.

Holewijn, M., and R. Heus (1991). Selection of fire fighters clothing for the Royal Netherlands Navy (in Dutch). Report IZF 1991 A-14, TNO Institute for Perception, Soesterberg.

ISO-FDIS-9886 Evaluation of thermal strain by physiological measurements, International Standardisation Organisation, Geneva, 2003.

Lotens, W.A. (1982) a comparison of three firefighter suits, part II: Ergonomics and practice tests (Een vergelijking van drie brandweerpakken II: Ergonomie en praktijkproeven.) Report Institute for Perception IZF 1982 C-14.

Lotens, W.A. (1978). Criteria for acceptable heat load, a discussion paper (Criteria voor maximaal toelaatbare warmtebelasting - een discussiestuk). Report IZF 1978-13, Institute for perception TNO, Soesterberg.

Lotens, W.A. (1987). Aramid or a wool/aramid mixture for use in firefighters clothing? (in Dutch). Report IZF 1987 C-5, TNO Institute for Perception, Soesterberg.

Lotens, W.A. (1988). Optimal design principles for clothing systems. Handbook on clothing RSG-7 (Nato), Chapter 17.

Lotens, W.A. (1989). Questionnaire field trial protective clothing for combat vehicle crewmen (in Dutch). Report IZF 1989-9, TNO Institute for Perception, Soesterberg.

Lotens, W.A. (1993). Labelling fire fighters clothing. Report IZF 1993 C-27, TNO-Institute for Human Factors, Soesterberg.

Malchaire, J., Kampmann, B., Havenith, G., Mehnert, P. and Gebhardt, H.J.,"Criteria for Estimating acceptable Exposure Times in Hot Working Environments: A Review", International Archive Occupational Environmental Health, 73, 2000, pp 215-220.

PrEN ISO/DIS 13506.2, Protective clothing against heat and flame -Test method for complete garments - Prediction of burn injury using an instrumented manikin (ISO/DIS 13506:1998) February 22, 1999.

Stirling, M. (2000) Aspects of fire fighter protective clothing selection. in: Ergonomics of Protective Clothing, Kuklane, K. and Holmer, I. (eds), National Institute for Working Life, Sweden, Nokobetef 6 and 1st European Conference on Protective Clothing, Stockholm, Sweden, May 2000, pp 269-276, ISBN 917045559 7, [WWW] Available from: www.niwl.se/ah/. 
Fig. 1, relation of work duration, intensity and environmental conditions with firefighter scenarios

Fig. 2, layout of propane burners (4 sets of 3 stacked units, total of 12 burners). Grey circle and arrows denote path taken by test participants in physiological load test. Star shows location of participants in climatic protection test.

Figure 3 the temperature $\left({ }^{\circ} \mathrm{C}\right)$ measured on the radiated front side of the fire-fighting garments under dry conditions. The bars that are connected with horizontal line are not statistically significant from each other

Figure 4 the relation between suit surface temperatures and tolerance times at the end of the radiation exposure in relation to the garments worn. The line denotes the best-fit line with suit A excluded.

Figure 5 temperature sensations on the body for A: legs, B: arms, and C: belly in relation to the garments worn in the climatic protection test. The values, which are connected with horizontal line, are not statistically significant from each other. $(2=$ comfortably warm $-8=$ very hot $)$

Figure 6 bar graph of sweating efficiency in relation to the clothing worn in the physiological load test. The bars, which are connected by a line, are not statistically significantly different from each other.

Figure 7 temperature sensation and moisture sensation for the whole body in relation to the clothing worn in the physiological load test. Results connected by a line are not statistically different from each other. (scale values as in appendix: a: $2=$ comfortably warm- $8=$ very hot; b: $2=$ slightly moist- $8=$ soaked)

Figure 8 the amount of water ( $\mathrm{g}$ ) absorbed by the clothing in relation to the clothing type for the rain test. Those scores, which are connected by horizontal line, are not statistically different from each other.

Figure 9 the leakage of the suits, as experienced by the test participants in the rain test, in relation to the garments worn. The results, which are connected by horizontal line, are not statistically different from each other. $(1=$ no $-7=\mathrm{a}$ lot $)$

Figure 10 limitations to the freedom of movement of the clothing under wet conditions for all fire-fighting suits. These scores which are connected by horizontal line are not statistically different from each other. $(1=$ none $-7=$ grave $)$

Figure 11 the occurrence of irritating spots (scouring) caused by the wet clothing in the rain test in relation to the garments worn. These scores which are connected by a horizontal line are not statistically different from each other. ( $1=$ none $-2=$ regularly $)$

Figure 12 the mean performance loss (\%) on the test " donning the suit". Results connected by a horizontal line are not statistically significant different. 
Figure 13, schematic representation of experimental set-up for visibility/conspicuity test, as modified from EN471. The angle between camera and light source for night time visibility is based on that for a car driver-car headlight on $100 \mathrm{~m}$ distance from the person.

Figure 14, Pictures taken from three motorcyclists ensembles using set-up of Fig. 13. Front, side and back view of participant while sitting on motorcycle. Examples shown are negatives for surface area analyses. For analyses of conspicuity pictures will be shown to panel as positives at various relevant distances.

Table 1 material properties of the investigated fire-fighting garments.

\begin{tabular}{|c|c|c|c|}
\hline Jacket & Outer layer & Middle layer & Liner \\
\hline $\mathrm{P}$ & Aramid (265 g.m $\left.{ }^{-2}\right)$ & Poly-urethane & Wool $\left(700\right.$ g.m $\left.{ }^{-2}\right)$ \\
\hline H2 (2-piece) & Aramid (275 g.m $\left.{ }^{-2}\right)$ & Gore-Tex $\left(170\right.$ g.m $\left.{ }^{-2}\right)$ & Wool $\left(230\right.$ g.m $\left.\mathrm{m}^{-2}\right)$ \\
\hline HC (coverall) & Aramid (275 g.m $\left.{ }^{-2}\right)$ & Gore-Tex (170 g.m $\left.{ }^{-2}\right)$ & Wool $\left(230\right.$ g.m $\left.\mathrm{m}^{-2}\right)$ \\
\hline A & Wool (660 g.m $\left.{ }^{-2}\right)$ & - & Wool $\left(440\right.$ g.m $\left.\mathrm{m}^{-2}\right)$ \\
\hline V & Aramid/Aircotex $\left(320\right.$ g.m $\left.{ }^{-2}\right)$ & - & Wool $\left(440\right.$ g.m $\left.{ }^{-2}\right)$ \\
\hline M & PBI $\left(268\right.$ g.m $\left.{ }^{-2}\right)$ & Gore-Tex $\left(122 \mathrm{~g} \cdot \mathrm{m}^{-2}\right)$ & Wool $\left(310\right.$ g.m $\left.\mathrm{m}^{-2}\right)$ \\
\hline REF & Wool/aramid & - & Wool $\left(430 \mathrm{~g} \cdot \mathrm{m}^{-2}\right)$ \\
\hline \multicolumn{4}{|l|}{ Trousers } \\
\hline $\mathrm{P}$ & Aramid (265 g.m-2) & Poly-urethane & - \\
\hline $\mathrm{H} 2$ & Aramid (275 g.m $\left.{ }^{-2}\right)$ & Gore-Tex $\left(170\right.$ g.m m $\left.^{-2}\right)$ & - \\
\hline $\mathrm{HC}$ & Aramid $\left(275\right.$ g.m . $\left.^{-2}\right)$ & Gore-Tex $\left(170\right.$ g.m $\left.\mathrm{m}^{-2}\right)$ & - \\
\hline A & Wool $\left(660\right.$ g.m $\left.\mathrm{m}^{-2}\right)$ & - & - \\
\hline V & Aramid/Aircotex (320 g.m $\left.\mathrm{m}^{-2}\right)$ & - & - \\
\hline M & Aramid $\left(180\right.$ g.m $\left.\mathrm{m}^{-2}\right)$ & Gore-Tex (122 g.m $\left.{ }^{-2}\right)$ & - \\
\hline REF & Wool/aramid & - & Wool/aramid \\
\hline
\end{tabular}


Table 2 the tolerance time (in seconds) which is just acceptable to participants, while stepping up and down a small bench in front of a radiant heat source $\left(7 \mathrm{kWm}^{-2}\right)$ at an air temperature of $118^{\circ} \mathrm{C}\left(\mathrm{SD}=4^{\circ} \mathrm{C}\right)$. Note: 120 seconds is maximal achievable time.

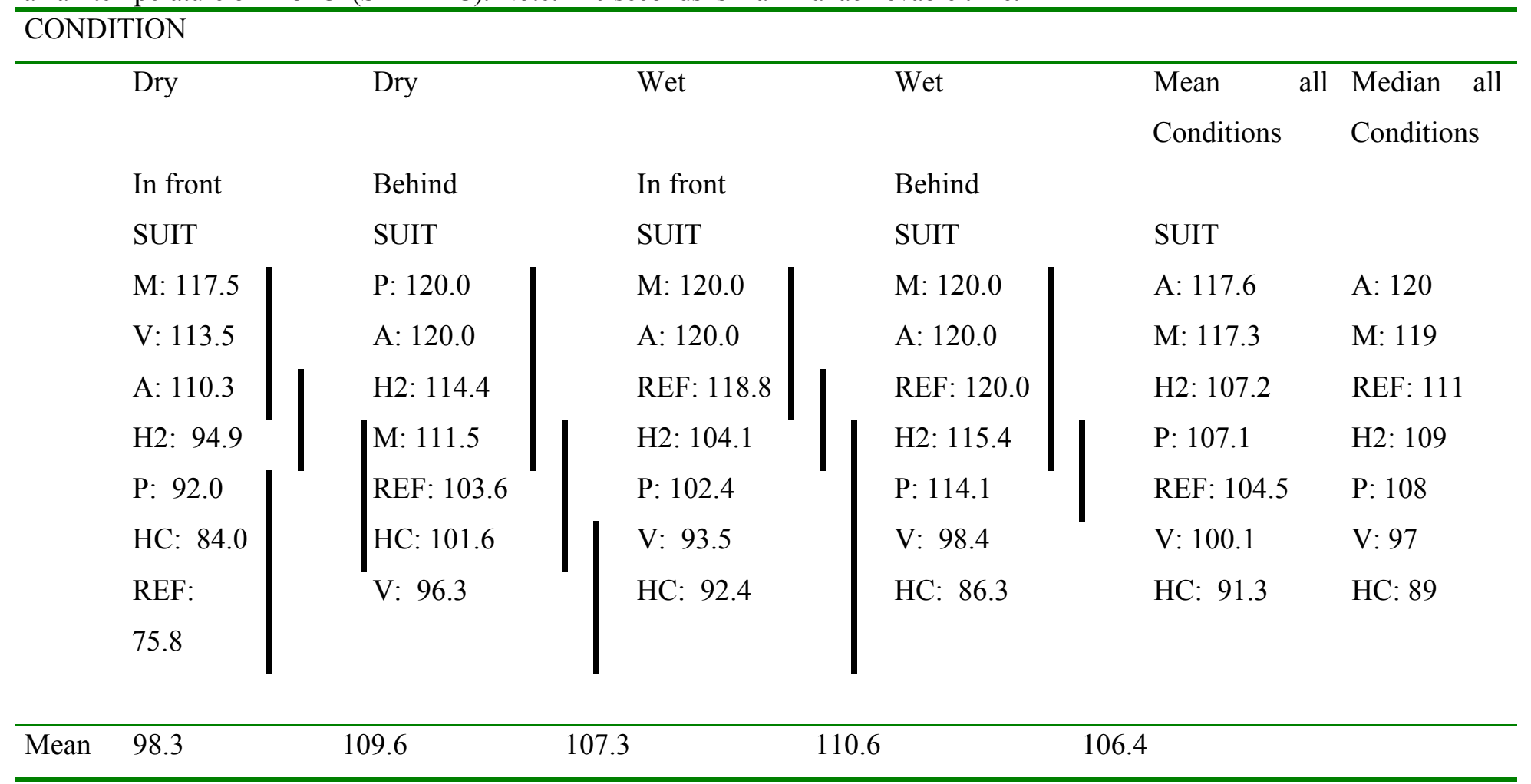

Results connected by a line are not statistically different from each other. 
Table 3 rating of fire-fighting garments based on the level of heat protection as measured in terms of tolerance time and suit temperature.

\begin{tabular}{lllllll}
\hline HC & V & REF & P & H2 & A & M \\
\hline-- & - & 0 & 0 & 0 & + & + \\
\hline
\end{tabular}

- $\quad=$ worse protection than the reference suit

0 = equal protection to the reference suit

$+\quad=$ better protection than the reference suit

Table 4 Tolerance times for an air temperature of $60^{\circ} \mathrm{C}$, a globe temperature of $90^{\circ} \mathrm{C}$ and a metabolic rate of $225 \mathrm{~W} . \mathrm{m}-2$.

\begin{tabular}{lll}
\hline Suit & $\begin{array}{l}\text { Tolerance time } \\
\text { (minutes) }\end{array}$ & $\begin{array}{l}\text { Standard deviation } \\
\text { (minutes) }\end{array}$ \\
\hline A & 21.4 & 2.8 \\
P & 22.1 & 3.9 \\
V & 22.6 & 2.5 \\
HC & 22.7 & 4.8 \\
H2 & 22.9 & 3.6 \\
REF & 25.0 & 4.0 \\
M & 25.0 & 4.8 \\
\hline Mean & 23.0 & 3.9 \\
\hline
\end{tabular}

Table 5 Evaporative and dry heat loss from the body in 7 suits for an air temperature of $60{ }^{\circ} \mathrm{C}$, a globe temperature of $90^{\circ} \mathrm{C}$ and a metabolic rate of $225 \mathrm{~W} . \mathrm{m}-2$.

\begin{tabular}{ll|l|l}
\hline Suit & \multicolumn{2}{l}{ Evaporation } & \multicolumn{2}{l}{ Dry heat loss } & Gain-loss \\
\hline A & 507 & -559 & 52 \\
REF & 483 & -573 & 90 \\
M & 383 & -499 & 106 \\
V & 371 & -497 & 106 \\
HC & 340 & -426 & 86 \\
P & 329 & -417 & 92 \\
H2 & 224 & -319 & 95 \\
\hline Mean & 377 & -470 & 93
\end{tabular}

The values, which are connected by a line, are not statistically different from each other. 
Table 6 overall scores for rain protection of the fire-fighting garments as compared to the reference suit.

\begin{tabular}{lllllll}
\hline A & Ref. & H2 & P & M & HC & V \\
\hline- & 0 & 0 & 0 & 0 & 0 & 0 \\
\hline
\end{tabular}

- $\quad=$ worse than the reference suit

0 = equal to the reference suit

Table 7 rating of the different fire-fighting suits for the four categories of use properties, and a total rating for all suits.

\begin{tabular}{lllll}
\hline Donning and doffing & Fit & Comfort & Compatibility & Total \\
\hline SUIT & SUIT & SUIT & SUIT & SUIT \\
A: 0 & A: 0 & A: 0 & A: 0 & A: 0 \\
H2: 0 & REF: 0 & REF: 0 & REF: 0 & REF: 0 \\
REF: 0 & H2: 0 & H2: 0/- & H2: 0 & H2: 0 \\
P: 0/- & P: $0 /-$ & P: 0/- & P: 0/- & P: 0/- \\
M: - & P: - & P: 0/- & P: 0/- & P: 0/- \\
P: - & M: - & HC: $0 /-$ & M: 0/- & M: - \\
HC: - & HC: - & M: 0/- & HC: - & HC: \\
\hline
\end{tabular}

$0 \quad=$ equal to the reference suit

$0 /-\quad=$ little less than the reference suit

- $\quad=$ less than the reference suit

- - $\quad=$ much less than the reference suit 


\section{Appendix A}

Questionnaire physiological load experiments

1 Use the scale below to give your judgement for how warm you found your

$A=$ feet

$\mathrm{B}=$ legs

$\mathrm{C}=$ arms and hands

$\mathrm{D}=$ belly and chest

$\mathrm{E}=$ back

$\mathrm{F}=$ shoulders

$\mathrm{G}=$ head

$\mathrm{H}=$ whole body

(put the respective character on the proper spot on the line below)

\begin{tabular}{|c|c|c|c|c|c|c|}
\hline 9 & 8 & 7 & 6 & 5 & 4 & 2 \\
\hline & $\begin{array}{l}\text { Very } \\
\text { hot }\end{array}$ & & hot & & $\begin{array}{l}\text { Uncomfortably } \\
\text { warm }\end{array}$ & $\begin{array}{l}\text { Comfortably } \\
\text { warm }\end{array}$ \\
\hline
\end{tabular}

2 Use the scale below to give your judgement on how sweaty you found your:

$\mathrm{A}=$ feet

$\mathrm{B}=$ legs

$\mathrm{C}=$ arms and hands

$\mathrm{D}=$ belly and chest

$\mathrm{E}=$ back

$\mathrm{F}=$ shoulders

$\mathrm{G}=$ head

$\mathrm{H}=$ whole body

(put the respective character on the proper spot on the line below)

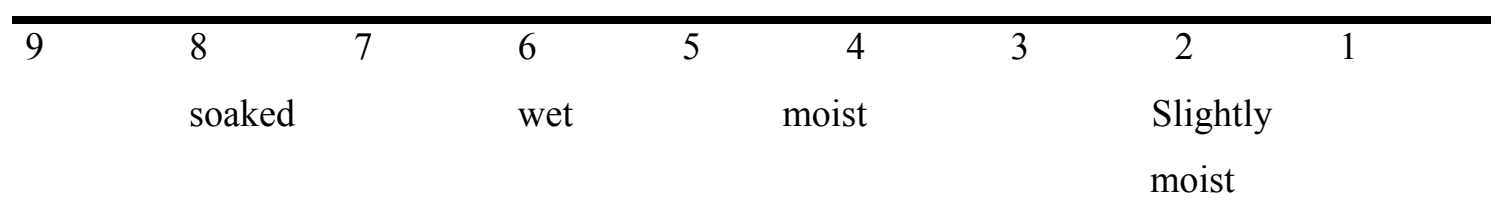

3. Did you experience any problems during this session (besides heat or sweating)?

YES / NO

If YES, please describe these problems

4. If you have any additional remarks related to your experience in this suit in this session, please write these down below 


\section{Appendix B}

Questionnaire waterproofness

1 did the clothing show any leakage?

\begin{tabular}{lllllll}
\hline 1 & 2 & 3 & 4 & 5 & 6 & 7
\end{tabular}

No

Extreme

leakage

leakage

2 if the clothing showed any leakage, what was the time when the first leakage was noticed? Please use the experimental clock for this.

The suit started to leak noticeably after minutes.

3 if any leakage occurred, in which places was this? Please use the drawing below to mark the spots, and the number of the order in which the leakage occurred. So, for example if leakage was noticed first at the sleeves and then at the back, you would put the 1 on the sleeves and the 2 on the back.

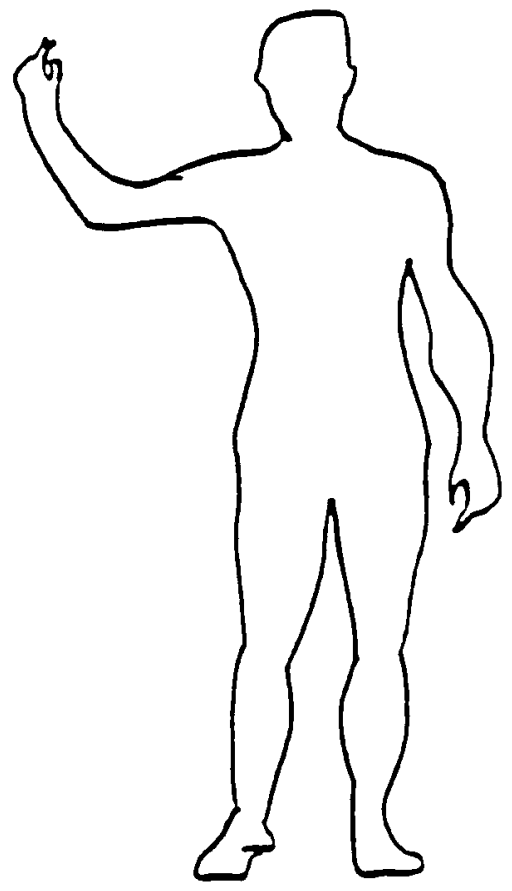

BACK

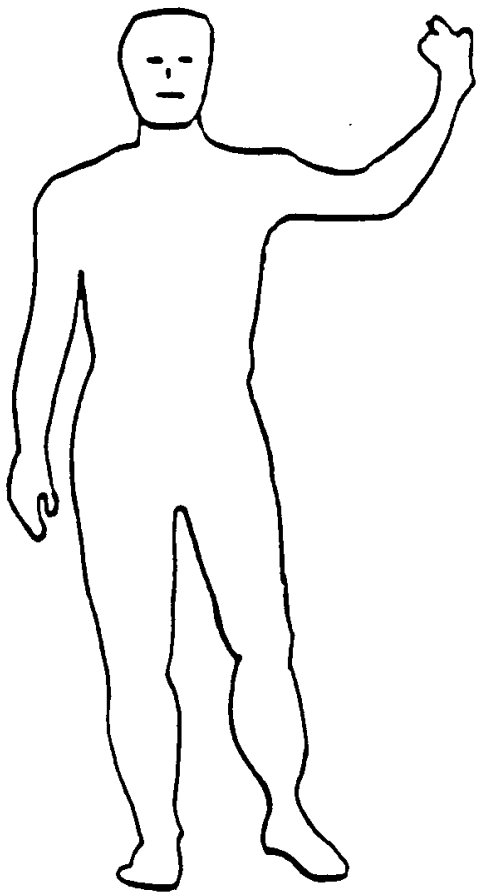

FRONT

4 How well was the closure of sleeves and trousers?

\begin{tabular}{lcccccc}
\hline 1 & 2 & 3 & 4 & 5 & 6 & 7 \\
Very & & & & & & Very \\
good & & & & & & Bad
\end{tabular}


5 in how far did the clothing reduce your freedom of movement when the clothing started to become wet?

\begin{tabular}{lcccccc}
\hline 1 & 2 & 3 & 4 & 5 & 6 & 7 \\
No & & & & & & Extreme \\
Reduction & & & & & & reduction
\end{tabular}

6 if you have circled the 5, 6, or 7 in question 5, please list below all places where you experienced the most important reductions in your freedom of movement.

7 How easy could you close your zipper when the suit was wet?

\begin{tabular}{lcccccc}
\hline 1 & 2 & 3 & 4 & 5 & 6 & 7 \\
Very & & & & & & Very \\
Easy & & & & & & difficult
\end{tabular}

8 if you have circled the 5, 6, or 7 in question 5, please list below all places where you experienced the most important reductions in your freedom of movement.

9 where

there any irritating/scouring spots in the suit? Yes / No

10 if you have answered the last question with a yes, please list below the spots where you noticed this, and list them in order of increasing nuisance.

11 please list below any remarks you think are important in relation to the judgement of the suits, especially for any topics, which were not listed in the questions above. Also any damage to this suit can be listed below. 


\section{Appendix C}

Questionnaire Comfort

Clothing fit and donning of the suit

1 how does the suit fit?

too small / good / too large

2 how is the length of trousers

too short / good / too long

3 how is the length of the sleeves?

too short / good / too long

4 how well can you bend forward? badly / acceptable / good would you like to comment on that?

5 how is the donning of the suit?

difficult / acceptable / easy

6 how can the suit be closed?

difficult / acceptable / easy

7 how well can you open and close the gloves?

difficult / acceptable / easy

8 what is your opinion on the closure?

bad / acceptable / good

\section{wearing comfort}

9 how is the freedom of movement in the suit?

bad / reasonable / good

if any limitation is present, could you describe this?

10 how well can you lift your legs?

badly / acceptable / good

11 how well can you lift your arms?

badly / acceptable / good

12 do you find this suit baggy?

13 how did you find the weight of the suit?

very much so / fairly / not at all

14 how warm is the suit (in the absence of fire)?

heavy / acceptable / light

15 do you get sweaty in the suit?

cold / neutral / warm

16 does the suit pinch somewhere?

very / fairly / not at all

if yes, where?

yes / no

17 do you feel any scouring of the suit?

yes / no

if yes, where?

18 did you get caught with the suit somewhere?

19 how was the doffing of this suit?

20 how good did sleeves and gloves match each other?

any comments on this?

21 how well did the trousers and the boots match each other?

badly / reasonable / good never / sometimes / often

difficult / acceptable / easy badly / reasonable / good any comments on this?

22 how well did the suit and the helmet match each other?

badly / reasonable / good

23 are there sufficient pockets?

yes / no 
24 are the pockets of sufficient size (for gloves, keys etc)?

25 are pockets easily accessible?

26 how well are at the pockets accessible while wearing SCBA

27 how is the fit of the suit while wearing SCBA? yes / no

yes / no

badly / reasonably / good

badly / reasonable / good

any comment on this?

28 please list below any remarks you think are important in relation to the judgement of the suits, especially for any topics, which were not listed in the questions above. Also any damage to this suit can be listed below.

\section{Appendix $\mathbf{E}$}

Example of an 8 (suits) by 8 (participants) Latin square experimental design. The characters denote the suit to be tested. This is a standard Latin square with each condition (suit) appearing once in each column (order in experiment), and the order is rotated for each row. More sophisticated designs are possible too. For help see: http://www.jic.bbsrc.ac.uk/services/statistics/latin.htm. When testing 4 suits with 8 participants, one can use a 4 by 4 Latin Square and copy this for subject 5 to 8 . In that case the second Latin Square can be mirrored so that the order is reversed in half the conditions.

\begin{tabular}{|c|c|c|c|c|c|c|c|c|}
\hline & \multicolumn{9}{|c|}{ Test order } \\
\hline $\begin{array}{c}\text { Participant } \\
\text { number } \downarrow\end{array}$ & $1^{\text {st }}$ & $2^{\text {nd }}$ & $3^{\text {rd }}$ & $4^{\text {th }}$ & $5^{\text {th }}$ & $6^{\text {th }}$ & $7^{\text {th }}$ & $8^{\text {th }}$ \\
\hline 1 & A & B & C & D & E & F & G & H \\
\hline 2 & B & C & D & E & F & G & H & A \\
\hline 3 & C & D & E & F & G & H & A & B \\
\hline 4 & D & E & F & G & H & A & B & C \\
\hline 5 & E & F & G & H & A & B & C & D \\
\hline 6 & F & G & H & A & B & C & D & E \\
\hline 7 & G & H & A & B & C & D & E & F \\
\hline 8 & H & A & B & C & D & E & F & G \\
\hline
\end{tabular}


Fig 1

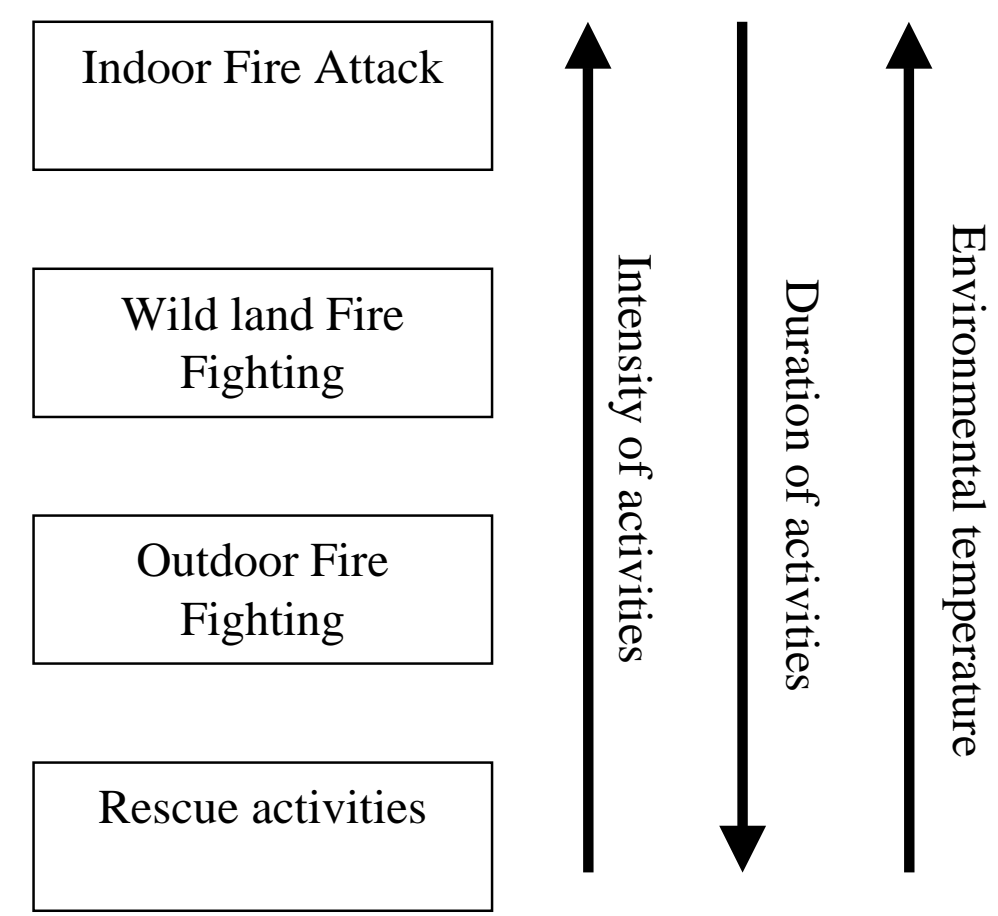




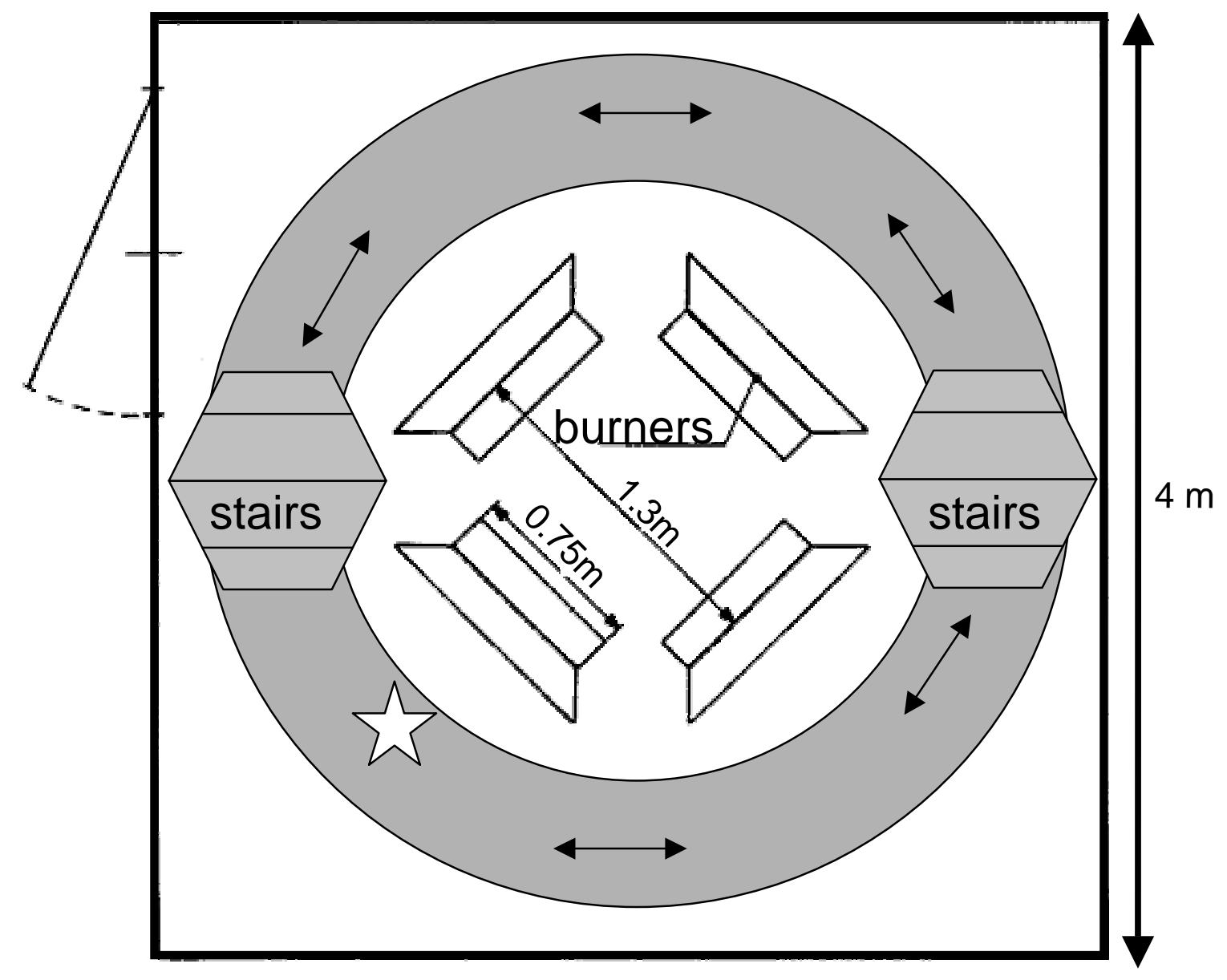

Fig 2 


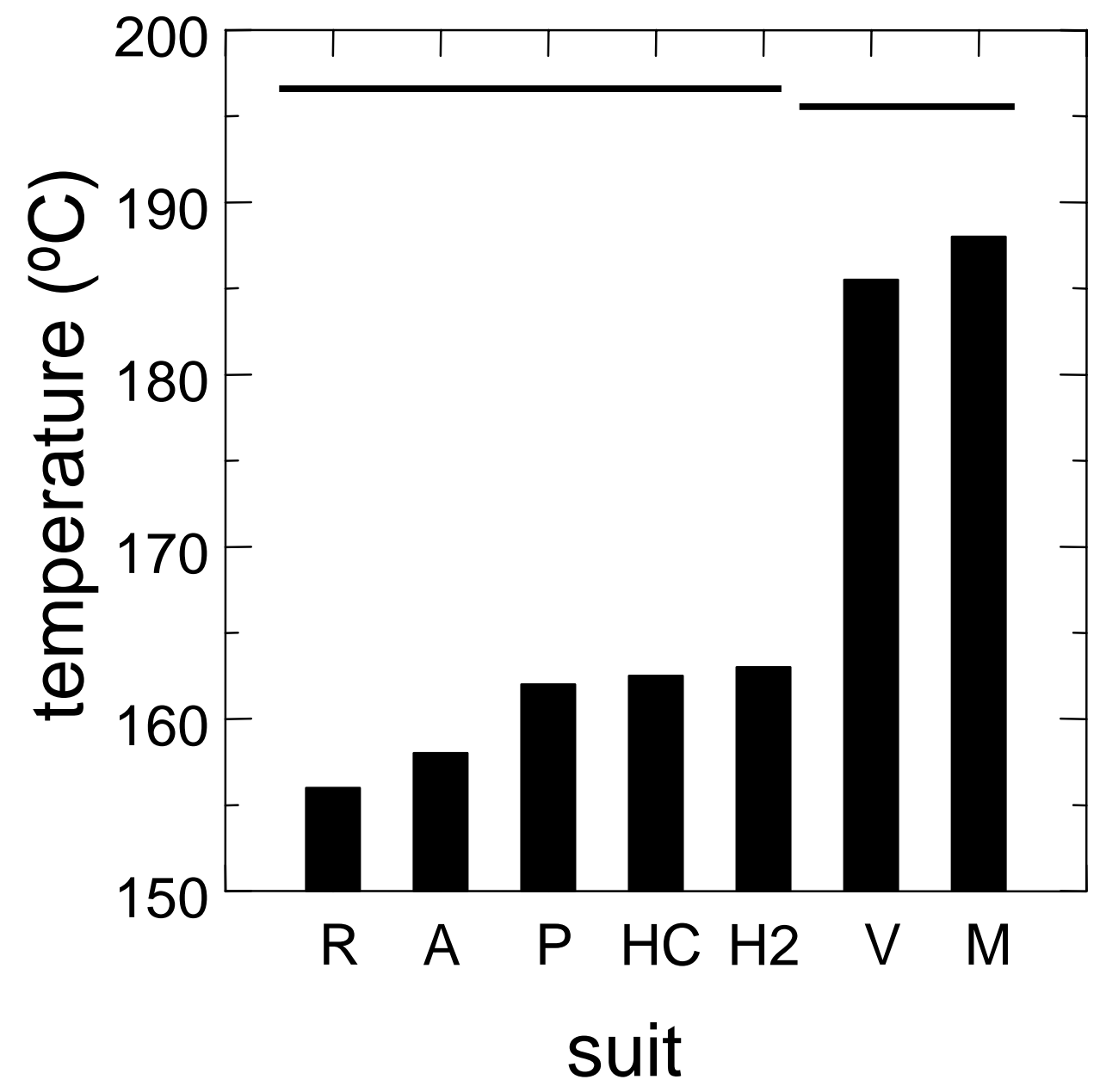

Fig 3 


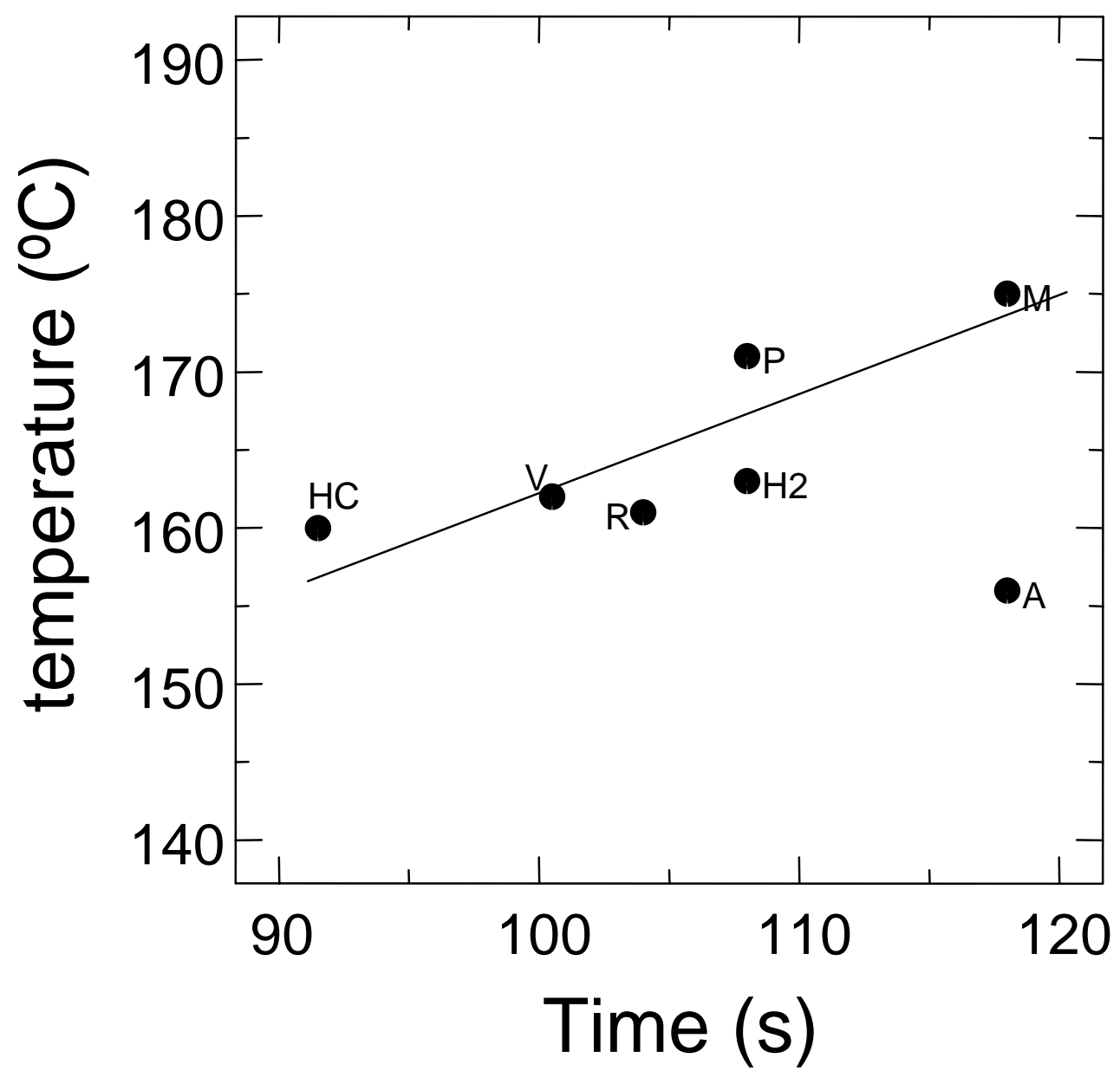

Fig 4 

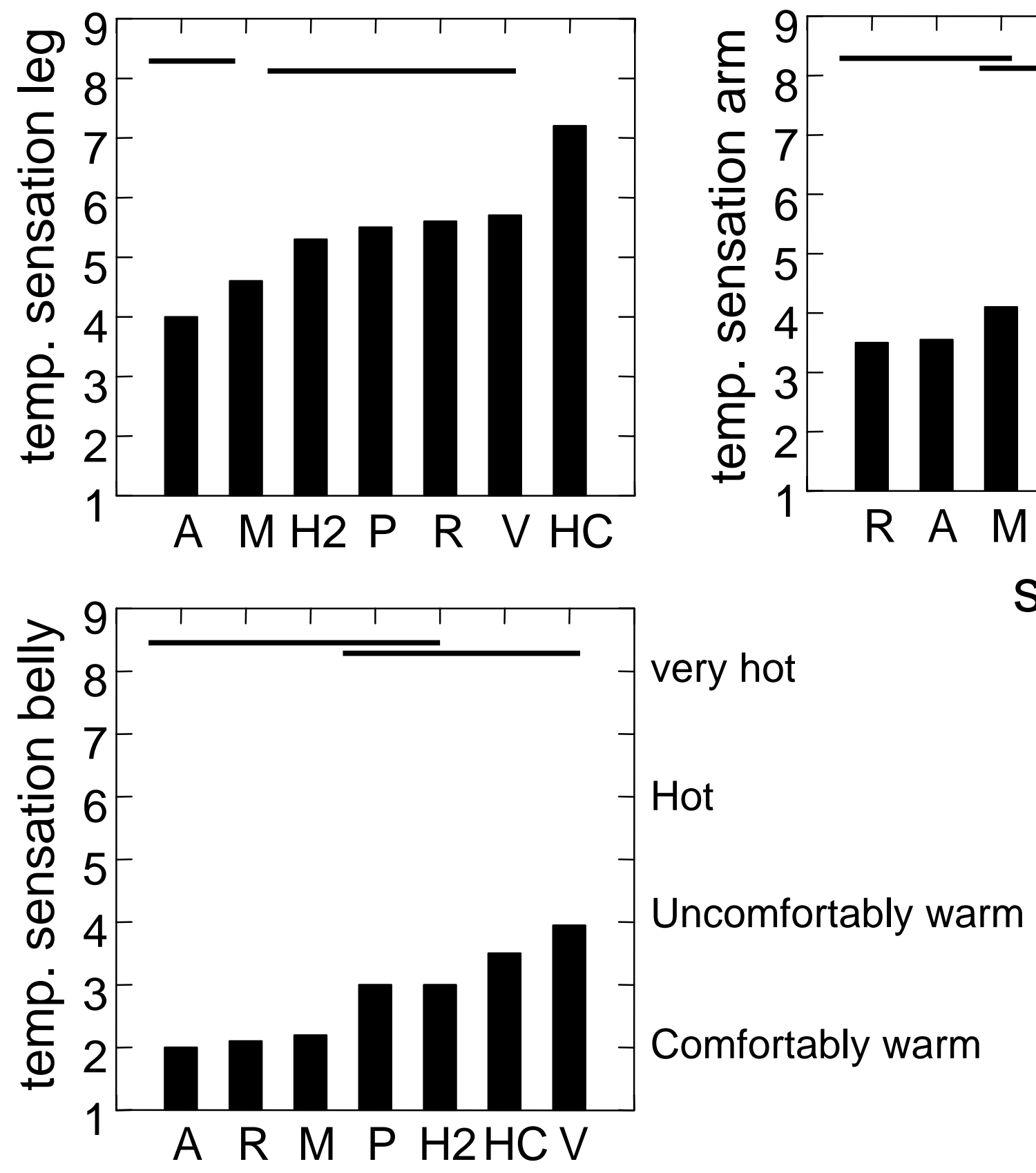

suit

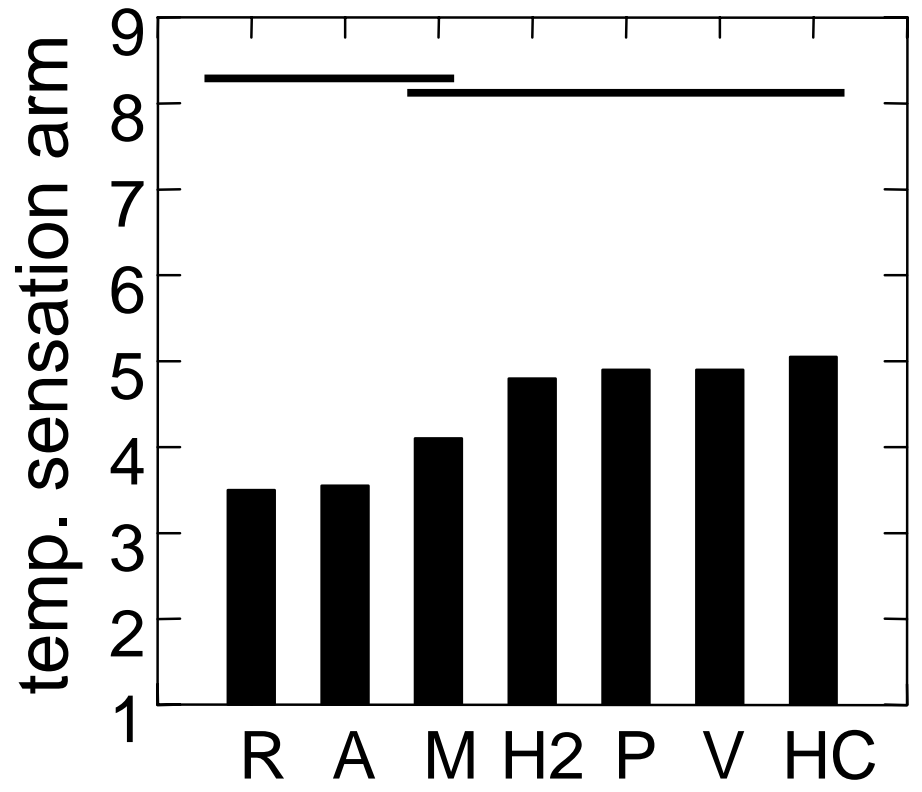

suit 


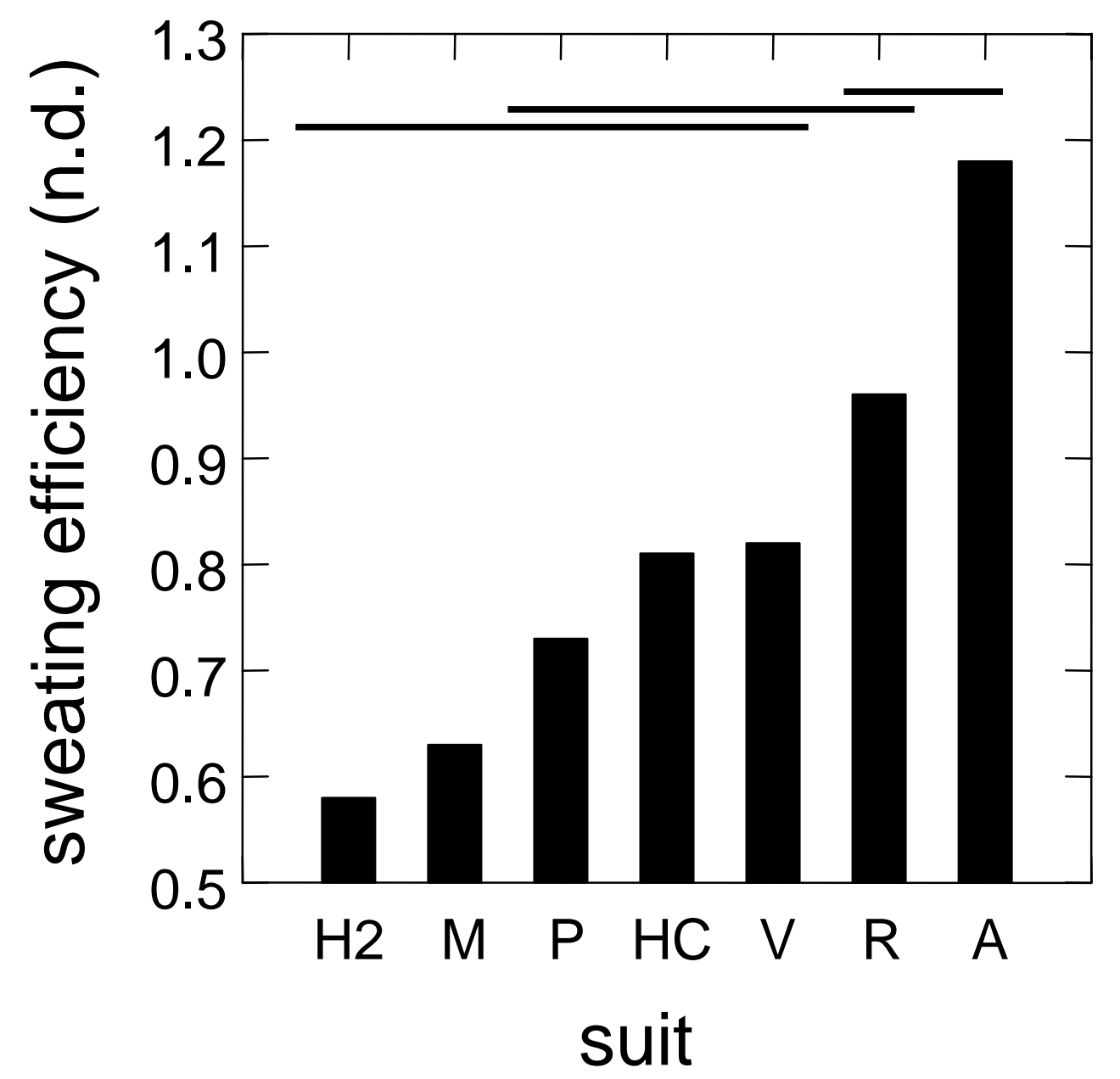

Fig 6 


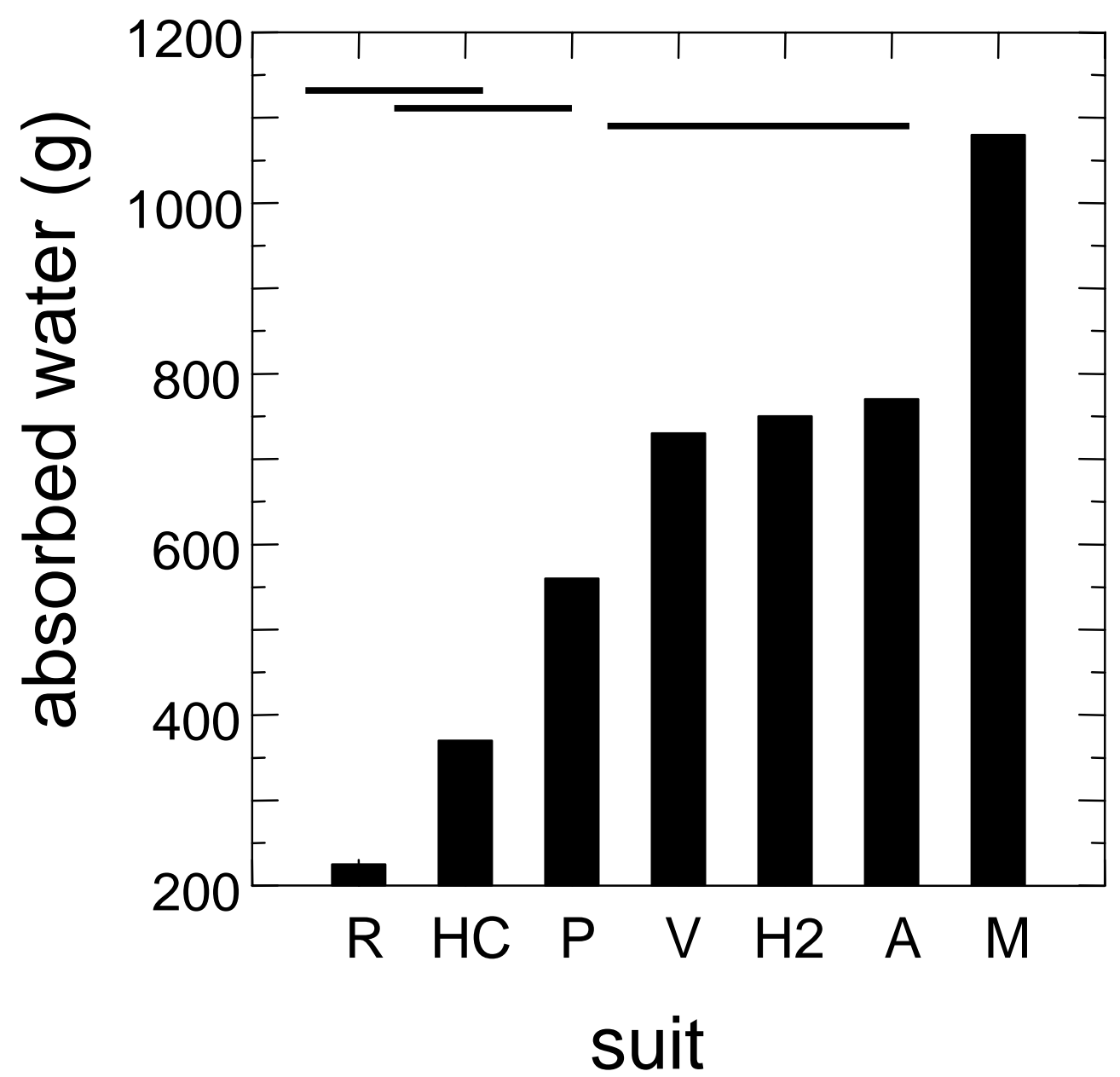

Fig 8 


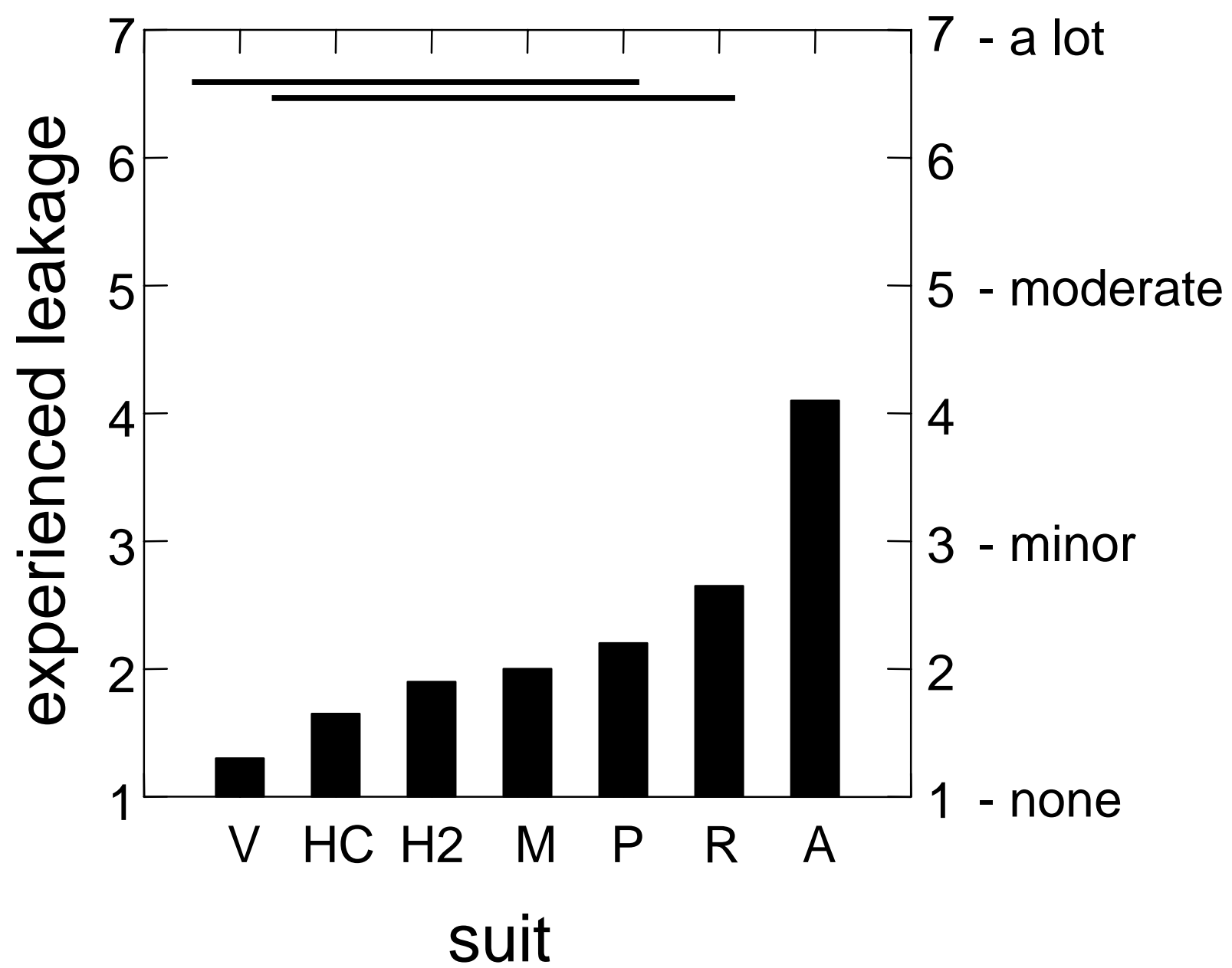

Fig 9 


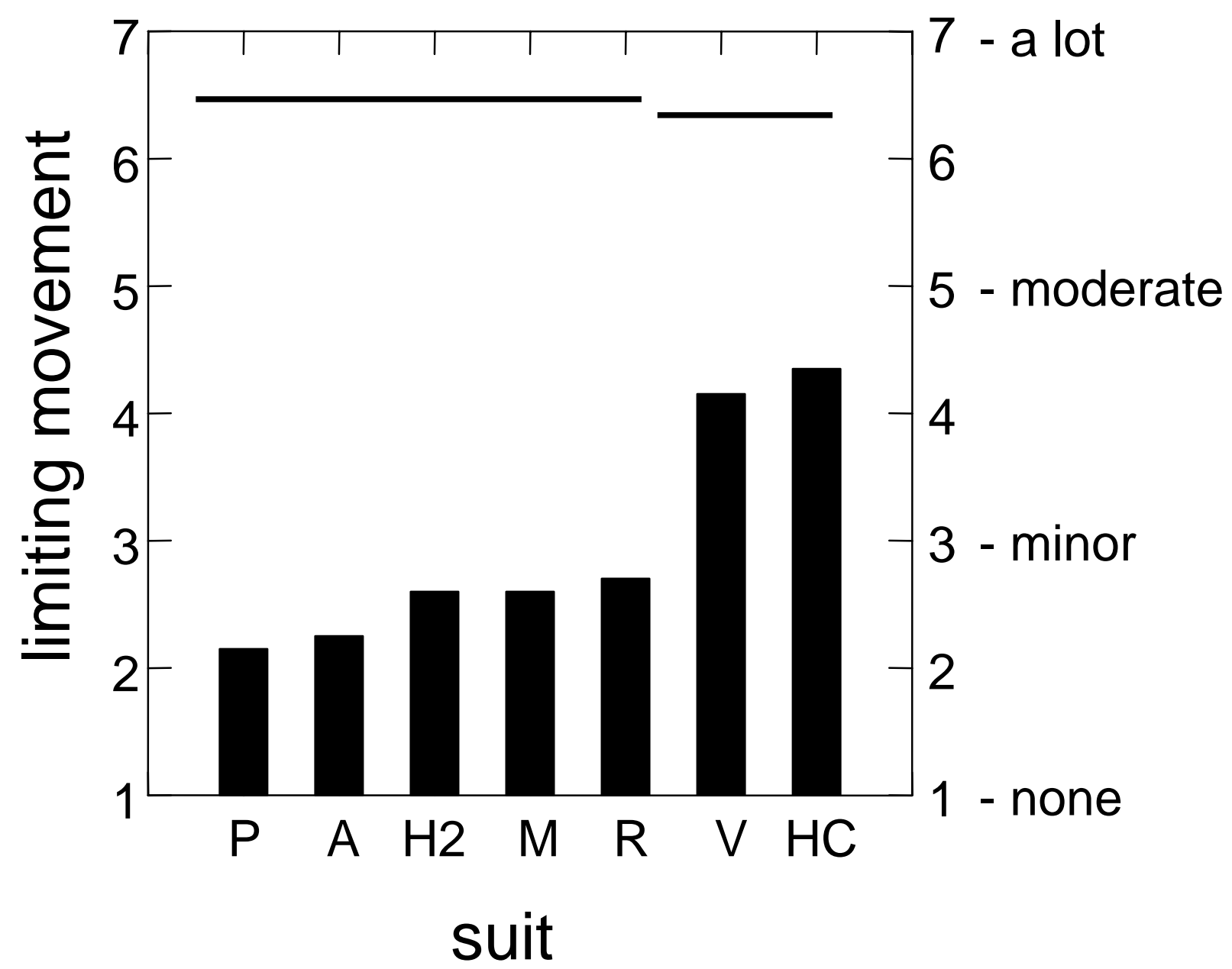

Fig 10 


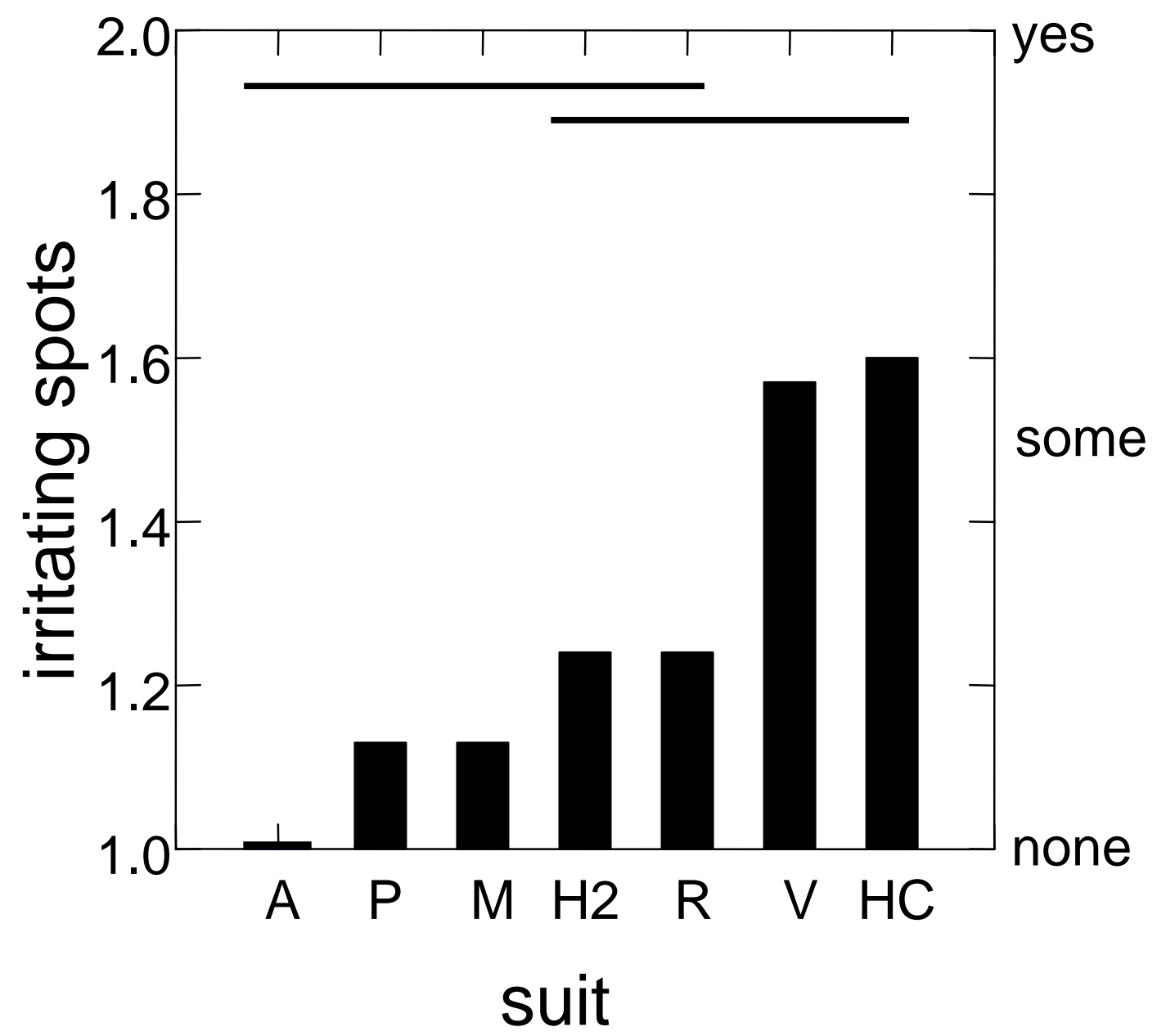

Fig 11 


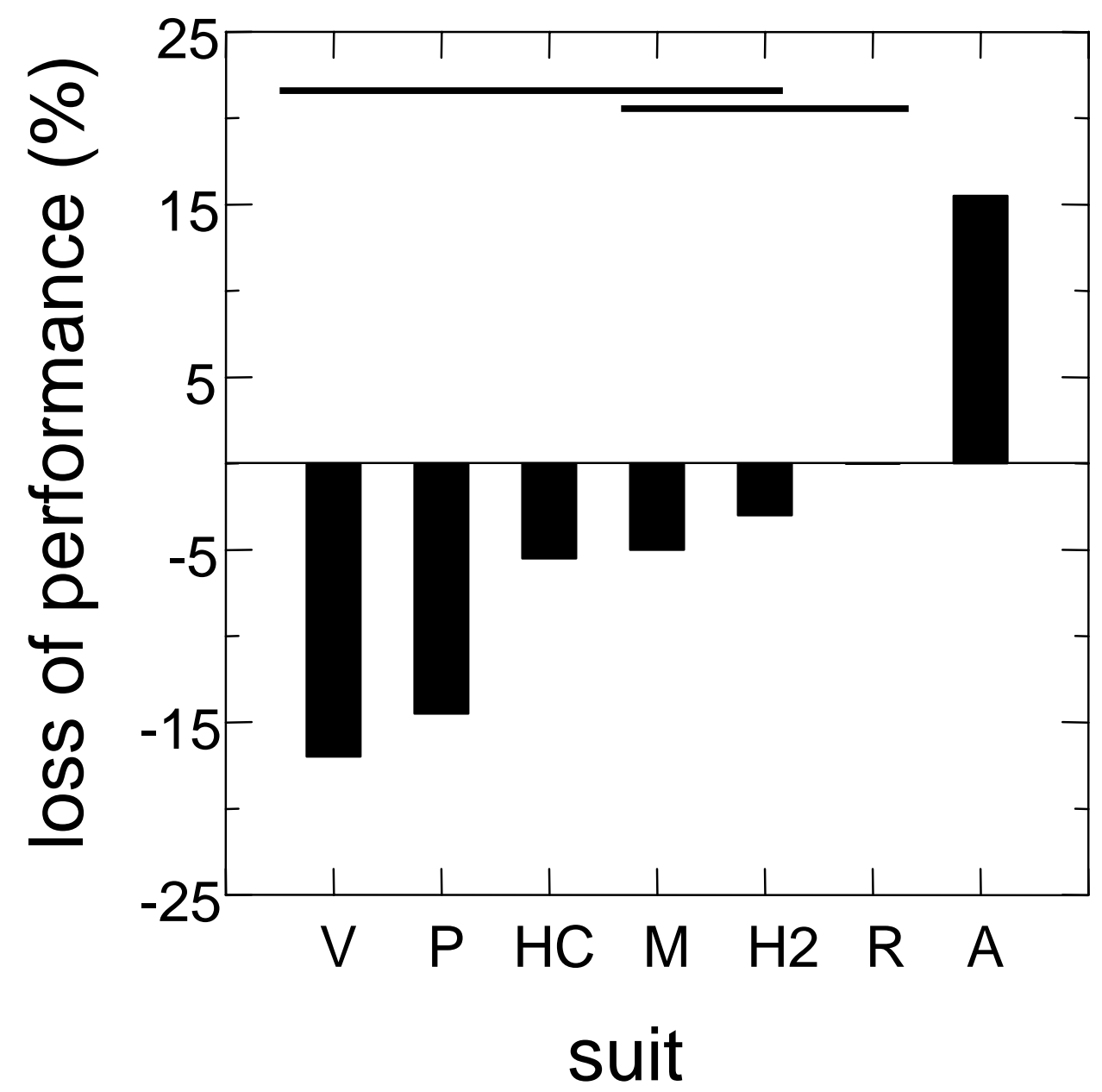

Fig 12 


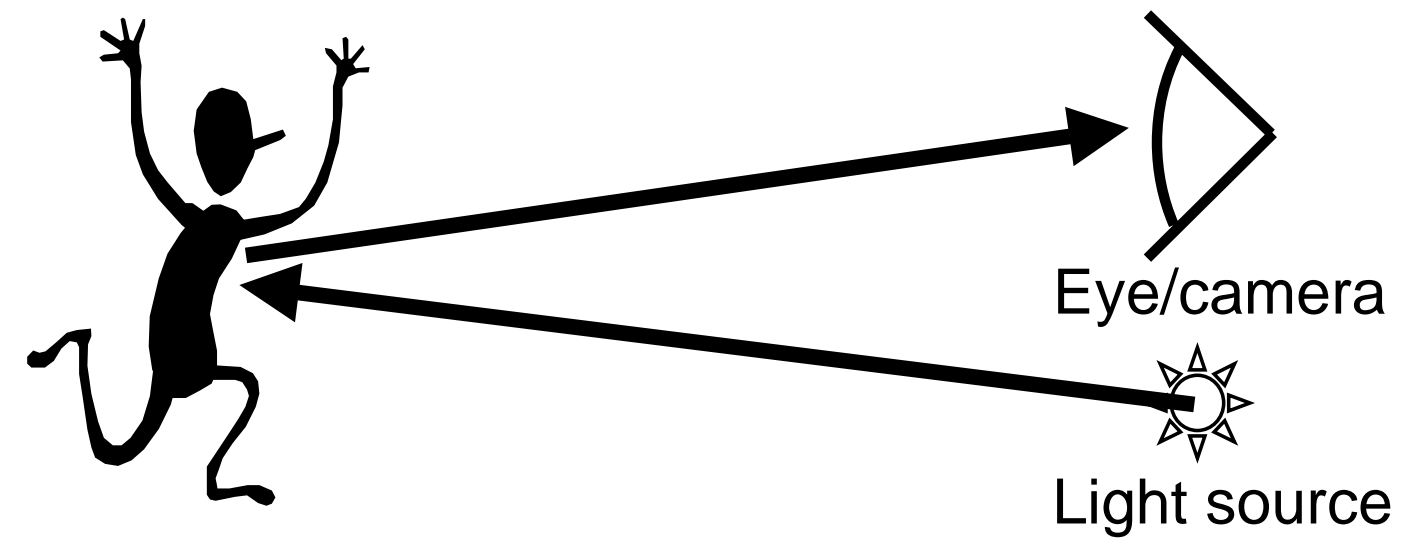

participant

Fig 13 


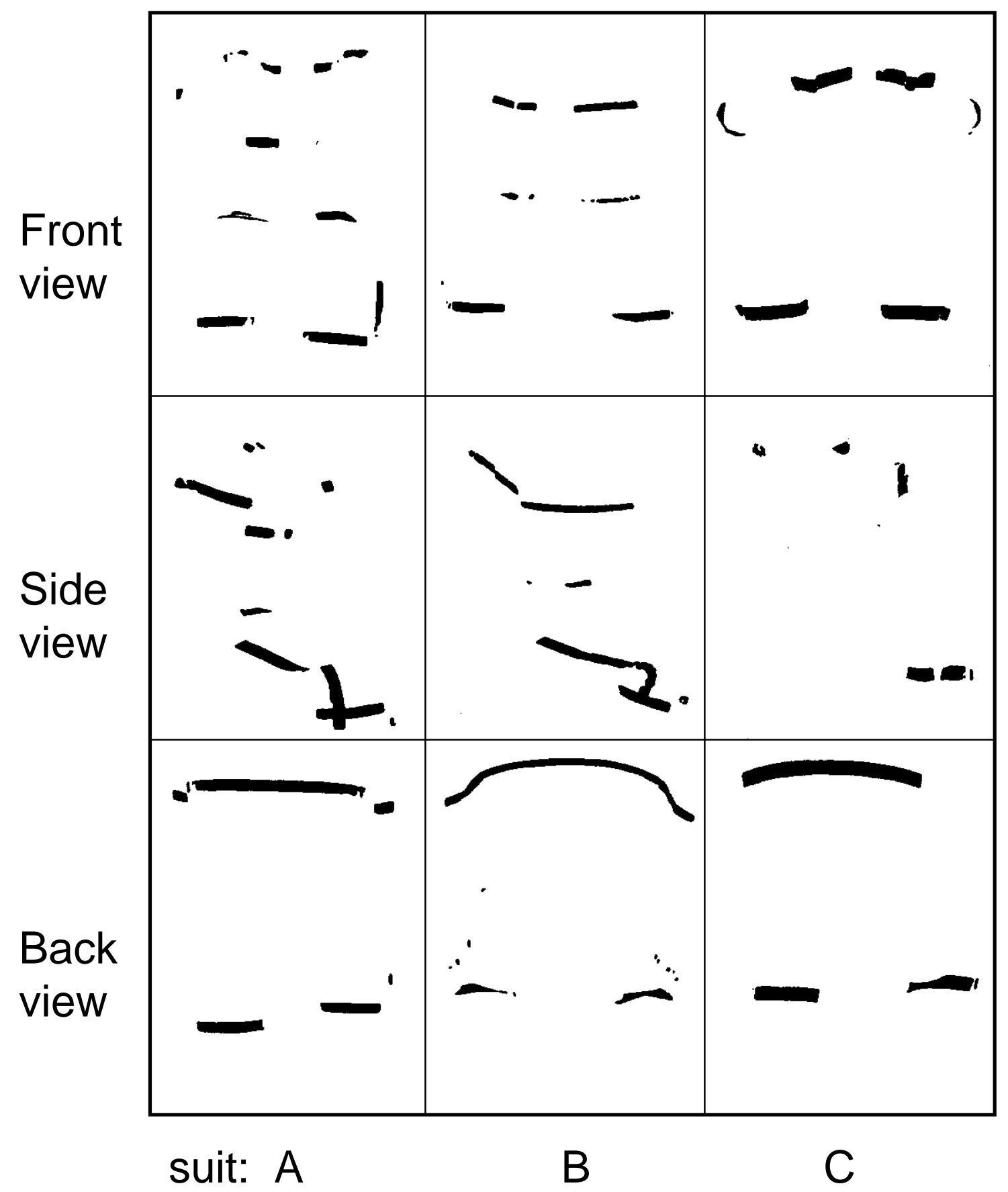

